This is an Accepted Manuscript of an article

Published by Taylor \& Francis in

Journal title: Quantitative Finance

Article title: How does bank credit affect the shape

of business groups' internal capital markets?

Published on: 01 Jan 2021

available online:

https://www.tandfonline.com/doi/full/10.1080/14697688.2021.1894349 


\title{
How Does Bank Credit Affect the Shape of Internal CAPital MaRkets?
}

\author{
by AndRea Giovannetti ${ }^{1}$ \\ University of Technology Sydney \\ andrea.giovannetti@uts.edu.au \\ Department of Economics 14-28 Ultimo Rd. NSW2007, Sydney
}

\begin{abstract}
In empirical literature, it is hypothesized that the persistence of Business Groups (BGs) is linked to the capability of easing the financing constraints of participating firms through the implementation of an internal capital market (ICM). ICMs enable capital relocation, thus partially offsetting disparities in accessing bank credit. I offer three contributions. First, I formally ground this idea with a dynamic model in which an ICM is endogenously generated as a function of the bank's lending policy and firms' production incentives. A novelty in the literature, the model contains a trickle-down mechanism which allows bank credit to circulate across firms via inter-firm loans. Second, I study the model to understand how the ICM reacts to shocks to the following empirically critical channels: the BG's debt-to-equity ratio, the profitability of production markets and, most importantly, the bank's credit rationing policy. The model disentangles the contribution of each channel on the shape of the ICM, as measured in terms of the intensity of firms' cross-subsidization. In particular, I discover a non-monotonic relationship between the latter dimension and the intensity of cross-subsidization. Third, I match stylized facts of the so called "Korean crisis" and apply the model to discipline some extant results of the empirical literature: I find that a tightening of the financial market, taken in isolation, would contribute to a densification of the ICM structure, reflecting the functioning of the credit-reallocation channel described in the literature. At the same time, the magnitude of such effect is not sufficiently strong to overcome the reduction in density as caused by the two alternative channels.
\end{abstract}

Keywords: Internal Capital Markets, Credit-Crunch, Financial Networks, Business Groups JEL Codes: G31, G32, G34

Word Count: 11180

\footnotetext{
${ }^{1}$ Email: andrea.giovannetti@uts.edu.au. Department of Economics 14-28 Ultimo Rd. NSW2007, Sydney. I am particularly indebted to the editor J. Gatheral, an anonymous referee, M. Anufriev, S. Currarini, T. Gall and A. Ianni for extremely helpful suggestions. I also warmly thank P. Bertolini, P. Campana, S. Corsi, S. Della Lena, D. Goldbaum, C. Di Guilmi, S. Galanis, A. Laiho, A. Landi, A. Manzini, G. Marotta, A. Mennuni, F. Nava, V. Panchenko, M. Piccione, P. Pin, A. Rosato, the participants of AFBC2017, the Asian Meetings of Econometric Society 2017 and attendees to seminars at Southampton, Modena and Paris 1 for useful comments. This research was supported by ESRC, BPM and the Australian Research Council through Discovery Project (DP170100429). The Author declares that he has no relevant or material financial interests that relate to the research described in this paper.
} 


\section{Introduction}

Business Groups (BGs) such as Samsung Group or Tata Group are conglomerates of legally independent firms owned by a common parent company, usually operating in multiple sectors. A critical feature of business groups across countries is the intense activity of cross-subsidization taking place between the Production Units (PUs, i.e. the firms) belonging to the group. For example, by buying and selling loans within their own group, banks belonging to a US Multibank Holding Company reallocate funds similarly to firms affiliated in a Korean chaebol or to companies in an Indian business house. Firms in Business Groups may decide to resort on pre-existing financing relationships or to establish new financial ties with other firms with which they share proximity under some dimension. The degree of formalization of linkages between members as well as the underlying organization ranges from loose horizontal to tight pyramidal structures (Samphantharak, 2006). Although evidence of BGs activity is widespread across economies at different stages of market development, the literature fails to identify a comprehensive theoretical driver for motivating the prevalence of such complex organization. A common denominator of BGs' activities around the world is the intense support provided to affiliate firms to overcome constraints on raising external capital ${ }^{2}$ (Hoshi et al., 1991).

This paper contributes to the strand of the literature which identifies in the BGs' capability to channel external liquidity into an internal capital market (ICM) the reason for their worldwide ubiquity. A large body of theories builds upon the assumption that in presence of capital market frictions, financially constrained firms may (be forced to) drift out of traditional financing venues and initiate complex inter-firm liquidity markets. While non-excluding for further explanatory layers, the idea that BGs are key for their capability to attenuate affiliates' financial constraints by means of the underlying ICM is appealing for its generality. For example, in the context of the Korean economy, characterized by a prevalence of conglomerates (i.e. the chaebols) of highly independent firms, Shin and Park (1999) find that a chaebol firm's investment is significantly affected by the cash flow of other firms within the same chaebol even though firms are independent legal entities. Along similar lines, Lee et al. (2009) isolate the link between the intensity of cross-subsidization - the chaebol's debt-to-equity ratio - and the chaebol's market efficiency. They show that the paralyzing effect on ICMs of liquidity regulations impacts the profitability of the whole conglomerate. Under the assumption that ICMs are a leading raison d'être for BGs, the analysis of BG's efficiency maps into the study of the direction of capital flows within the BG. In this regards, Almeida et al. (2015)

\footnotetext{
${ }^{2}$ Gopalan et al. (2007) provide evidence that more than $70 \%$ of intra-group loans in Indian business groups are funded by external debt financing. I am grateful to a referee for pointing out the latter remark.
} 
show that a low-productivity to high-productivity firms capital reallocation exists within ICMs and that such flow improves the efficiency of BGs. In particular, they find that it is generally true that BGs reallocate funds to member firms with greater investment opportunities. In terms of the financing advantage, Almeida et al. (2011) show that groups use internal revenues to set up or acquire capital-intensive firms, which are more likely to be constrained in financial markets. Parallel to (or on top of) this channel, tax-saving and financial resilience may shape the architecture and the direction of inter-firm capital allocations (see, in particular, Nicodano and Regis, 2019 and Luciano and Nicodano, 2014). I postpone the discussion on this literature to Section 1.1.

In this paper I make three contributions. First, I motivate observed inter-firm lending by formalizing a trickle-down mechanism in which bank's liquidity flows across PUs. The mechanism sheds light on a credible mechanism for explaining how liquidity circulates in ICMs. I argue that when banks ration credit and discriminate across borrowers by linking the amount of extendable credit to a measure of the firms' pledgeable assets, it is incentive compatible for a group of financially disconnected PUs within a BG to initiate a layer of financial transactions. In the model, inter-firm lending incentives are linked to the structure of the real markets in which firms operate, the financial market determining the bank's lending policy and the BG's debt-to-equity policy. A key aspect of the model lies in the way capital circulates across a ICM. Coherently with a pervasive empirical regularity of ICMs (see, for example, Buchuk et al., 2014 and Almeida et al., 2011), capital trickles-down from larger and more mature low-productivity firms to younger and smaller high-productivity firms. To capture this feature, I innovate the theoretical literature by constructing a dynamic internal capital market. In every period new heterogeneously cash-constrained firms (i.e. the newcomers) access the ICM in order to get capital from firms that already settled in it (i.e. the mature firms). Similar to empirical ICMs (Lee et al., 2009), firms in the model are legally independent production units. This raises two important questions on the mechanics of capital transfer: to what extent lenders can control their borrowers' lending decisions and how are borrowers paired to lenders?

I address the first issue by assuming that capital is exchanged via pairwise interactions and that a lender has no direct control on further capital transfers operated by her borrowers. Importantly, given the incentive structure, capital may trickle down from low-productivity to high-productivity firms, allowing for possibly multiple exchanges of the same assets. Importantly, the fact that exchanges are efficient only on pairwise basis moderates the overall capability of BGs to reach efficient allocations.

I resolve the second issue discussed above by introducing a probabilistic firm pairing protocol. The probabilistic mechanism has an important advantage, that is, it is flexible 
in the specification of the exchange rule adopted in the specific ${ }^{3}$ pairwise transaction. ICMs are unregulated markets in which PUs come to idiosyncratic pairwise arrangements, therefore the menu of available contracts can be very sparse. A probabilistic matching device is therefore a flexible tool that allows for a broad spectrum of unobservable and noisy contracts. Because of the probabilistic pairing protocol, the trickle-down mechanism applied to a finite number of firms $N$ can potentially generate a very large number of lending configurations. I resolve the complexity of interactions by characterizing a stationary distribution measuring, for any time period, the proportion of lenders with a given intensity of cross-subsidization and cash holding. This distribution provides a representation of the equilibrium supply side of the ICM.

From there, I study how real and financial market factors affect via local exchange incentives the supply shape of the ICM, as measured in terms of the intensity of crosssubsidization. Therefore, the stationary distribution of cross-subsidization is the unit of analysis for the rest of the paper. This leads to my second contribution. I study how the intensity of cross-subsidization changes as a function of the BG's debt-to-equity ratio, the profitability of production markets and the bank's lending policy. For the first two channels, I devise a monotonic relationship between each factor and the intensity of crosssubsidization. For the last channel, I show that the relationship between ICM structure and bank's borrowing and lending rates is complex and potentially non-monotonic, as a result of two tensions characterizing bank-firm relationship: first, the bank directly affect the amount of credit available to firms (and borrowers in the ICM), but at the same time, it also indirectly affects the internal leverage capability of firms. While the monotonic relationship is not achievable in general, I show that it can be re-established if the bank's policy is sufficiently aggressive. This is the case if the relative cost of bank's liquidity (respectively, the risk of the investment) is sufficiently low (respectively, high).

Lastly, I use the model in simulations to better understand the interplay between external and internal financing on the shape of the supply side of the ICM. Using the above channels I generate a scenario compatible with the so called "Korean Crisis", a complex multi-channel shock that hit the Korean economy in 1997-1998. The shock bore long-lasting consequences on the shape of Korean chaebols' ICMs (Almeida et al., 2015). The model disentangles the simultaneous effects generated by the shocks on the equilibrium distribution of the ICM cross-subsidization. Coherent with the empirical literature $^{4}$, the effects I consider are given by a bank credit-crunch that limited ICMs

\footnotetext{
${ }^{3}$ In the model, I capture the high degree of idiosyncrasy governing inter-firm capital flow transactions characterizing empirical ICMs (see, for example, Khanna and Yafeh, 2007) by assuming that exchanges are subject to pairwise bargaining between PUs.

${ }^{4}$ See, for a broad discussion on the causes and the consequences of the Korean crisis, Almeida et al., 2015 and Lee et al., 2009.
} 
external finance ( captured in the model by higher costs for banks to obtain liquidity on markets and higher interest rates), new regulations aimed at limiting cross-subsidization ${ }^{5}$ and a slow-down in the real economy. Overall, the BG's lending structure reacts to the complex crisis with a reduction of the ICM density (matching the findings of Lee et al., 2009), but once we decompose the general effect, we also find that such effect is mostly due to the cap on debt-to-equity ratio, rather than a shock on rates, in line with Lim (2012) and Borensztein and Lee (2002).

Methodologically, at the core of market dynamics there is a model of random network formation ${ }^{6}$. To my knowledge, this is the second work adopting a network approach to study the properties of ICMs. From a complementary yet different perspective, Almeida et al. (2011) reconstructed the expansion of Korean Chaebols by tracking the layer of direct and indirect ownership relations and the network centrality of each production units. Our aim here is instead to isolate a theoretical formation mechanism which explains how bank liquidity trickles down into inter-firm markets so that the realized inter-firm liability structure matches the empirical regularities outlined above. Furthermore, the mechanism can be used for deriving the aggregate effect of macro-shocks in an environment of local interactions.

The rest of the paper is organized as follows. In Section 2 I construct the dynamic ICM. First, I establish a formal relationship between individual PUs' demand for capital, bank finance and inter-firm finance. Next, I introduce the dynamic mechanism for ICM's formation. In Section 3 I derive the central theoretical result of the paper: the characterization of a class of stationary distributions tracking the ICM's cross-subsidization. I study the distribution to understand the role of debt-to-equity regulations, market profitability and cost of finance in shaping the lending structure of ICMs. In Section 4, first, I quantitatively assess the individual effect of each of the above channels on several features related to the structure of ICM. Second, I calibrate the model to generate a multi-channel shock similar to the so called Korean Crisis and use it to disentangle the effect of each channel on the inter-firm lending structure of a ICM. All proofs are collected in the Appendix.

\footnotetext{
${ }^{5}$ Empirically, this coincided with a regulatory shock that prohibited cross-loan guarantees and crossshareholdings forced debt-to-equity ratios under $200 \%$ (Lee et al., 2009).

${ }^{6}$ See Jackson and Rogers (2007) and Vega-Redondo (2007) for a discussion of recent contributions. Random networks allow to project the effect of local interactions into the structural properties of a resulting aggregate system. However, with respect to the cited models, the formation mechanism here is pairwise efficient and is driven by micro-founded incentives.
} 


\subsection{Related Literature}

Indeed, other mechanisms may motivate the ubiquity of ICMs. When control involves private benefits, ICMs may be sustained by unilateral incentives of integration. A body of literature has focused on the one-side incentives of merges and hierarchical control. In a seminal contribution, La Porta et al. (2002) found that when share-holding is concentrated, there might be an incentive for the control group to expropriate minority share-holders and tunnel resources from the periphery (i.e. newly acquired firms) of the group to the center of it. In this light, the incentive for group formation is a function of the stake-holder majority's powers and therefore, business groups are a mechanism for resource-concentration. However, incentives for the creation of business groups and fluid ICMs may be aligned between the firms participating to a business group, regardless of idiosyncratic features such as the group's structure and each participant's relative power. Within-group collusive tactics may be adopted in order to deter market-entrance (see for instance Cestone and Fumagalli, 2005) or to gain political leverage which can be used to push forward the group's special interest (Leuz and Oberholzer-Gee, 2006). Although the focus of the present work is on proposing and formalizing a financing motive driving the formation of ICMs, the sense of the probabilistic pairing mechanism is to allow for noisy contracts and (group-level) inefficiency, reflecting the multiplicity of empirical intra-group financial arrangements.

This work suggests that BG's efficiency can be improved to some extent by ICMs: ICMs may smoothen PUs' access to external finance through a trickle-down mechanism based upon a noisy pairwise bargaining process. However, BGs may enhance affiliates' value also through other channels. An important literature investigates the value-enhancing role of intra-group state-contingent guarantees between legally separated affiliates. These are intra-group arrangements widely observed in empirical BGs around the world ${ }^{7}$. In a risk-neutral world with no state-contingent guarantees, Leland (2007) studies the relation between capital structure and corporate value in a trade-off model of optimal leverage where connected PUs can be merged in one single legal entity. Mergers may destroy value when the loss of limited liability generates gains from higher optimal debt (and tax savings) which fail to compensate higher contagion risk due to lower cash-flow diversification. Luciano and Nicodano (2014) generalize Leland's model by introducing conditional guarantees. The departure is critical as the authors discover that, by enabling both coin-

\footnotetext{
${ }^{7}$ In a seminal contribution, Boot et al. (1993) underlines the ubiquity of state-contingent guarantees between members of holding-groups (e.g., comfort letters, that is promises of rescue sent by the parent to the affiliates lenders) and provides a reputation-based mechanism for which conditional guarantees may be preferred to enforceable cross-guarantees as they provide the holding company with flexibility in managing financial impairment together with the benefits of legal separation among the holding company entities. I refer the reader to the literature review of Luciano and Nicodano (2014) for evidence on the use of intra-group guarantees in empirical BGs.
} 
surance and deflection of contagion risk, conditional guarantees allow for an asymmetric shift of the leverage profile across BG's affiliates jointly with an overall expanded debt capacity. Close to the network formation spirit of my paper, Nicodano and Regis (2019) expands Luciano and Nicodano (2014) by proposing a general trade-off model in which a controlling entity optimally decides the ownership share of two subsidiaries, thus allowing for truly complex structures. Depending on the tax saving - contagion trade-off, these range from hierarchical (with full or partial subsidiary ownership by parent) to horizontal.

\section{Model}

\subsection{Set-Up}

In this section ${ }^{8}$ I first describe the model set-up in chronological order and then discuss its main features. Consider an economy made of one loan facility and a large population of production units (PUs), $N \equiv\{1,2, \ldots, \bar{t}\}$. A PU $i \in N$ is a firm performing four tasks. First, $i \in N$ purchases via cash a homogeneous and divisible input valued $K_{i}$ on an anonymous spot market at unitary cost $c$. Second, input $K_{i}$ is transformed via a strictly concave technology $f(K)$ into an equally homogeneous and divisible output $q_{i}$. Third, $i \in N$ sells output $q_{i}$ on a competitive market generating a unitary revenue equal to $p$. Forth, $i \in N$ may lend some of the cash obtained from the bank to other firms $j \in N$. The lending facility is a bank that performs the two following tasks: first, it acquires liquidity at competitive cost $\tau$ (for example, from money markets). Secondly, it lends cash to firms at competitive rate $r$. The economy is dynamic and it unfolds along a discrete timeline $t=0,1,2, \ldots,(\bar{t}+1)$, grouped in three distinct phases (see also Figure $1)$.

The first phase coincides with period $t=0$. In period $t=0$ each firm $i$ is born with a randomly assigned endowment of assets $e_{i} \geq 0$. I assume that $e$ is uniformly distributed according to $e \sim \mathcal{U}\{0, \bar{e}\}$, with $\bar{e}>0$. For simplicity, firms are cashless. Each firm $i \in N$ collateralises $e_{i}$ and obtains cash $\omega_{i} \geq 0$ from the loan facility. The loan facility freely screens endowment $e_{i}, \forall i \in N$ ex-ante the loan is issued, and, depending on financial parameters $\tau$ and $r$ and an exogenous collateral rate $\chi$ set over the borrower's assets, optimally lends a quantity of cash $\omega_{i}=\omega_{e_{i}}$, where

$$
\omega_{e_{i}} \equiv \omega\left(e_{i} ; r, \tau, \chi\right), \quad i \in N
$$

and since the bank supplies all firms $i \in N$ endowed with $e=e_{i}$ a symmetric amount of

\footnotetext{
${ }^{8} \mathrm{I}$ am profoundly grateful to an anonymous referee who provided excellent guidance for restructuring this and the next sections.
} 
credit, the above is equivalent to

$$
\omega_{e} \equiv \omega(e ; r, \tau, \chi), \quad e \in\{0, \ldots, \bar{e}\}
$$

From the solution to the bank's problem (See Section 2.4) I obtain the equilibrium bank cash distribution, $p_{\omega} \sim \Omega$, spanning a cash endowment $\omega_{e}$ for each asset endowment $0 \leq e \leq \bar{e}$.

The second phase of the model corresponds to periods $t \in\{1,2, \ldots, \bar{t}\}$. In this phase, each firm $i \in N$ satisfies her outstanding demand for cash $D_{i} \geq 0$ by sequentially entering, one per period in increasing order, in the internal capital market (ICM), formally defined as DEFINITION 1 (Internal Capital Market). For each period $t \in\{1,2, \ldots, \bar{t}\}$, let the internal capital market (ICM) be the pool of PUs $t^{\prime} \in N_{t-1}=\{1,2, \ldots, t-1\} \subset N_{\bar{t}}$. Let a generic PU entering the ICM at $t, i=t$ be the newcomer, and firm $t^{\prime} \in N_{t-1}$ be the mature PU, respectively. Furthermore, let $K_{t^{\prime}}(t) \geq 0$ and $\bar{s}_{t^{\prime}}(t-1) \geq 0$ be the cash endowment (i.e. the loanable funds) and the outstanding transfers (i.e. the total amount of outstanding loans) of $t^{\prime} \in N_{t-1}$ at time when firm $t$ enters in the ICM, respectively.

Due to the sequential structure, I can write $D_{i}=D_{t}$. I assume that the additional source of cash $D_{t}$ is constrained by exogenous corporate regulations $\alpha \geq 0$ and $\beta \geq 0$ that bound - at ICM-level - the maximum amount of funding firms can individually obtain from (provide to) other firms. More precisely, the following assumption holds

ASSUMPTION 1 (Cross-Subsidization). A proportional constraint $\alpha$ (respectively, $\beta$ ) applied on $\omega_{i}$ bounds the quantity of loans $i \in N$ can get from (respectively, provide to) other PUs in the ICM .

In every period $t$, newcomer $i=t$ collects her outstanding demand for cash $D_{t}$ as follows. A random matched with one firm $t^{\prime} \in N_{t-1}$ is created according to a protocol I characterize in detail in Section 2.7. If parties agree to exchange, cash $\ell_{t t^{\prime}}>0$ is transferred from $t^{\prime}$ to $t$ against a pairwise-set interest rate $\iota_{t t^{\prime}}>0$ and the lender (respectively, the borrower) will revise the amount of loanable funds $K_{t^{\prime}}$ and loans $\bar{s}_{t^{\prime}}$ (respectively, the outstanding demand for cash $D_{t}$ ) to reflect the realized exchange. Whether the parties agree to exchange or not, the match dissolves and the process iterates to new matches until firm $t$ exhausts her outstanding demand $D_{t}$ and settles in the pool of potential lenders $N_{t}$. Subsequently, the economy progresses to $t+1$ and the process repeats.

The last phase of the model coincides with the conclusive period of the economy, $t=\bar{t}+1$. There, each firm $i \in N$ optimally chooses an investment level $I_{i}\left(\omega_{i} ; p, c, \alpha, \beta\right)$, with $I_{i}$

\footnotetext{
${ }^{9}$ See for instance Almeida et al. (2015) and Almeida et al. (2011) for a discussion of the real effect of regulations on the empirical counter-part of $\alpha$ and $\beta$ in the context of Korean Chaebols.
} 
constrained by (see Assumption 1)

$$
-\beta \omega_{i} \leq I_{i} \leq \alpha \omega
$$

so that $i \in N$ uses a total cash amount equal to $\left(I_{i}+\omega_{i}\right)$ to purchase input $K_{i}$. Input $K_{i}$ is transformed into the divisible output $q_{i}$ via a strictly concave production technology $f(\cdot)$. Eventually, output $q_{i}$ is sold on the competitive output market generating a unitary revenue equal to $p$. Payment of bank and firm credit takes place ex-post sales.

Parameters. The following coefficients are taken as fixed by agents populating the model: the market structure, defined as the vector $M \equiv(p, c, \alpha, \beta, r, \tau, \chi)$, the parameters $(0, \bar{e})$ regulating the endowment distribution and the production technology $f(\cdot)$.

Notation. Subscripts indicate parameters, terms in brackets are variables. In the rest of the paper, I refer to $i \in N$ as a generic PU. When dealing with the dynamics of the ICM, I label each period $t$ 's newcomer $i$ and any generic mature firm $j$, with $i, j \in N$, such as $i=t$ and $j=t^{\prime}$. Lastly, I refer to firm $i$ 's bank loan $\omega_{i} \geq 0$ as firm $i$ 's type. Since most of results in the paper are general in the sense that they are type-dependent rather than firm-dependent, when possible, the firm identifier will be dropped.

\subsection{Solution and Main Features of the Model}

The main goal of this paper is to isolate a nexus between the financial and macroeconomic environment and the evolving shape of the dynamic ICM. The ICM will be studied in terms of its lending side by tracking the distribution of inter-PU cross-subsidization. To solve the dynamic model, I further characterize the incentive structure by introducing the following set of assumptions

ASSUMPTION 2 (Financing Structure). For any given $P U i \in N$,

1. Bank loans are determined ex-ante $I_{i}$. As the bank is exogenous to the ICM, bank rates are non negotiable and enter as a cost in the determination of $I_{i}$.

2. Cross-subsidization is constrained by internal debt-to-equity regulations. PUs are leverage-constrained and the internal debt mechanism is such that inter-firm pairwise rates $\iota$ do not enter directly in the determination of $I_{i}$.

3. Inter-firm pairwise rates $\iota$ are on top of the bank rate $r$. As a consequence of Assumptions 2.1-2.2, bank rates exogenously bound the internal debt structure of the ICM.

Assumption 2.1 allows me to study how the dynamics of the inter-firm lending structure react to shocks to external finance ${ }^{10}$ holding the latter as fixed, or in other words, I disci-

\footnotetext{
${ }^{10}$ Technically, this assumption enables the unique stationary distribution of inter-firm loans (see Section $3.1)$.
} 
pline the relationship between the sources of finance to isolate first-order effects of bank shocks. Indeed, there are many environments where banks operate above the competitive margin (see Buchuk et al., 2014) and ICMs may help improving the credit spread through the coinsurance implicit in cross-subsidization. Improving the debt capacity of affiliates is a leading motivation for the creation of complex business structures (see Section 1.1 for a discussion of the main contributions of this approach, in particular Nicodano and Regis, 2019 and Luciano and Nicodano, 2014). The first part of Assumption 2.2 is consistent with the empirical organization of BGs around the world (Lee et al., 2009). The second part enables an arbitrage opportunity: it is possible for PUs to be at the same time borrowers and lenders in the inter-firm market ${ }^{11}$. Relatively to Assumption 2.3, it is widely observed that intra-group lenders compute loan rates in terms of spreads from conventional money markets (see for instance Allen et al., 2019 and Buchuk et al., 2014), with the noticeable exception of Indian BGs (Gopalan et al., 2007).

Given Assumption 2, I can now introduce the information structure and the decisionmaking of agents populating the economy.

Information Structure and Solution of the Model. At $t=0$, the bank observes endowments $e_{i}, \forall i \in N$, financial parameters $(r, \tau, \chi)$ and market conditions $(p, c)$, on the ground of which ${ }^{12}$ the bank maximizes expected profits by optimally designing a lending scheme $\omega_{e}, \forall e \in\{0,1, \ldots, \bar{e}\}$. In period $t=0$, each firm $i \in N$ observes her own endowment $e_{i}$, her cash loan $\omega_{i}$, the elements of the market structure $(p, c, \alpha, \beta)$ and technology $f(\cdot)$, on the ground of which $i \in N$ optimally plans the investment level $I\left(\omega_{i} ; p, c, \alpha, \beta\right)$. In period $t=1, \ldots, \bar{t}$ each firm $t$ and $t^{\prime} \in N_{t-1}$ additionally observes the vector of cash endowments $\left\{K_{t^{\prime}}(t)\right\}_{t^{\prime}=1}^{t-1}$ and $D_{t}$. Every matched couple $t$ and $t^{\prime}$ observes $\ell_{t t^{\prime}}$ and $\iota_{t t^{\prime}}$.

The model is endowed with three critical innovations relative to extant models of ICM structure (see, e.g., Almeida et al., 2015). First, the economy is non-stationary. This structure is motivated by the fact that firms populating empirical ICMs have heterogeneous age and such maturity strongly correlates with firms' financing behaviour (Khanna and Yafeh, 2007). As a second critical feature, similar to Almeida et al. (2015), firms have heterogeneous asset endowments $e$. An innovation of the present setting is that the ICM is complemented with a formal financial sector. This is accessed by firms ex-ante entering the ICM. To isolate a clear-cut link between financial markets and ICMs, firms are cashless ${ }^{13}$, yet each firm $i \in N$ can collateralize $e_{i}$ and obtain cash $\omega_{e}$ from the loan

\footnotetext{
${ }^{11}$ Note however that the Assumption is moderated by the fact that in this paper intra-group exchanges have to be incentive-compatible on pairwise basis to realize (see Section 2.6)

${ }^{12}$ Since corporate regulations $\alpha$ and $\beta$ dictating inter-firm exchanges are unknown to the bank, the bank will take firms' sales $p \cdot q_{i}$ as random variable.

${ }^{13}$ The introduction of an intermediate case with heterogeneous cash endowments would allow to con-
} 
facility. Importantly, corporate regulations $\alpha$ and $\beta$ dictating inter-firm exchanges are unknown to the bank, and as such firms' sales $p \cdot f(K)$ are taken as random variable. The process governing bank-firm lending relationship will be entirely captured by the equilibrium bank cash distribution $p_{\omega} \sim \Omega$, which dictates the degree of heterogeneity of firms' cash endowments. Indeed, $p_{\omega}$ will play an important role since it contributes to determine the size and thickness of the ICM. The third element of novelty of this work is given by the protocol used by PU $i \in N$ for collecting $D_{i}$. Given her outstanding demand for cash, $i \in N$ is paired with one or multiple firms residing in the ICM. The cash is exchanged against an interest rate $\iota$ (a price), obtained as the result of pairwise bargaining $^{14}$.

In order to study how the environment affects the properties of the lending side of the ICM, I will focus on the asymptotic properties of the ICM and make the following assumption

ASSUMPTION 3 (Temporal Structure). Assume that the last phase of the model takes place indeterminately later, that is $\bar{t} \rightarrow \infty$.

In the rest of the section, I will first determine each firm's target investment and the bank lending scheme, on the ground of which I can derive the ICM-level demand and supply of capital. Lastly, I will introduce inter-firm exchanges and study the evolution of the lending side of the ICM.

\subsection{Determination of Target Investment Structure $(t=0)$}

In period $t=0$, each firm $i \in N$ endowed with $e_{i}$ receives a bank loan corresponding to $\omega=\omega_{e_{i}} \geq 0$ (determined in Section 2.4) and optimally sets her investment target $I_{i}=I\left(\omega_{i} ; p, c, \alpha, \beta\right)$ by solving a one-shot problem. As firms are symmetric conditional on type $\omega$, in the following I drop the firm identifier and claim each firm endowed with

sider a scenario in which loans descending from bank credit can be (partially) crowed-out in favor of intra-group credit exchanged based upon internal resources. Albeit heterogeneous cash endowments can be a relevant venue for studying certain phenomena (such as the resilience of business groups to external shocks Allen et al., 2019), it would not alter the effects of bank discrimination on the topology of the ICM, the focus of the present study.

${ }^{14}$ The use of entrusted loans for inter-firm capital flows instead of governance-related mechanisms (e.g. share issuance) and the related wide spectrum of interest rates is predominant in many types of ICMs (Allen et al., 2019; Buchuk et al., 2014). The bargaining mechanism and the pairing device I devise are agnostic on the degree of control exerted by lenders on borrowers, thus allowing for a broad spectrum of (noisy) configurations. Furthermore, the resulting formation protocol is such that economic incentives, rather than property rights are the main motivating driver for the formation of ICMs. 


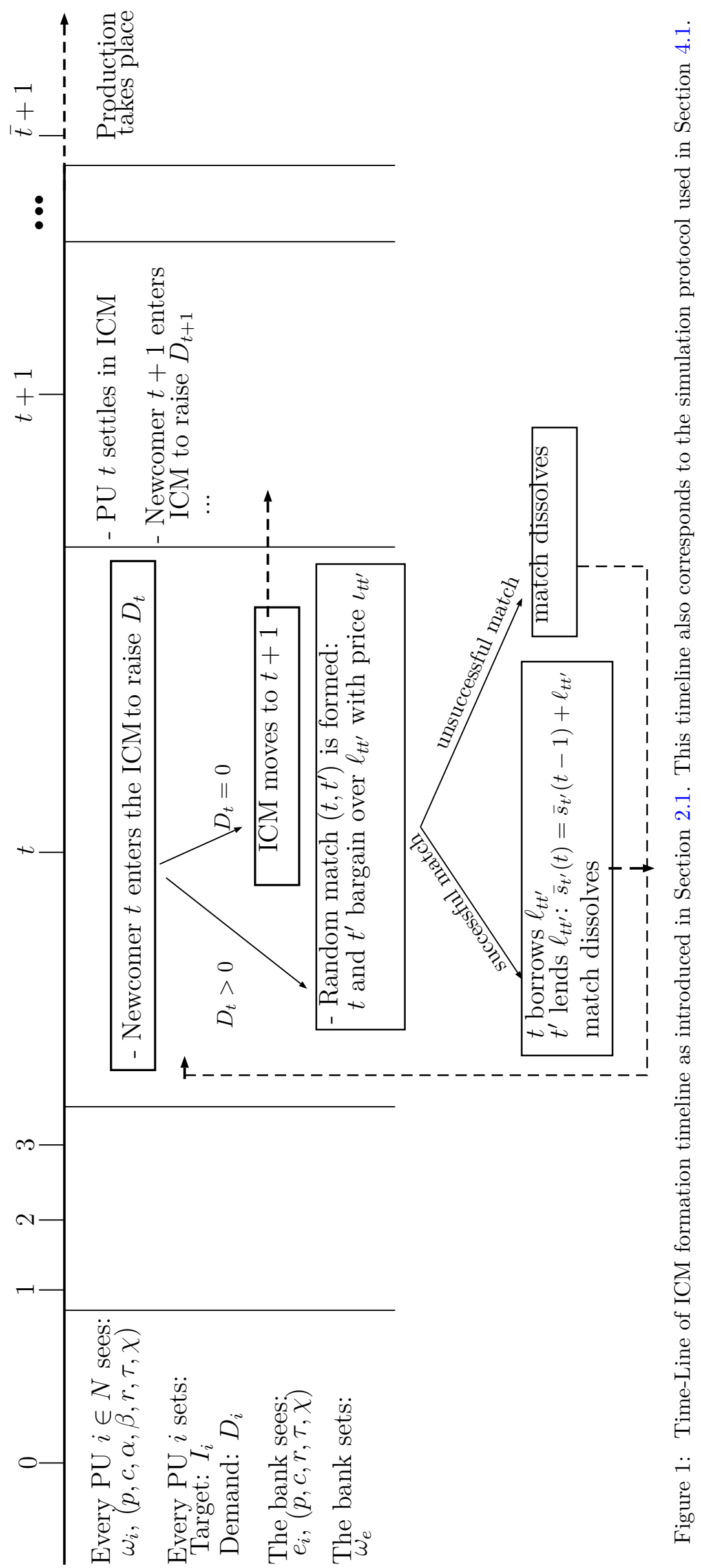


$\omega \in \Omega$ optimally adjusts $I_{\omega}$ to $I_{\omega}^{*}$ by solving the following problem

$$
\begin{gathered}
\max _{I_{\omega}} \Pi_{\omega}=p \cdot f\left(I_{\omega}+\omega\right)-c \cdot\left(I_{\omega}+\omega\right) \\
\text { s.t }: \quad-\beta \omega \leq I_{\omega} \leq \alpha \omega,
\end{gathered}
$$

in which $I_{\omega}$ is the investment, and may take negative values in case of excess cash resources. In order to isolate the nexus between inter-firm and bank lending, I assume that transformation costs are negligible ${ }^{15}$ and therefore impose that

$$
c=r
$$

that is the level of investment is adjusted by considering the leverage constraint and the cost of bank lending, and is independent from any additional rate charged on interfirm loans (as long as Assumption 1 is maintained). Intuitively, because bank rates are non negotiable, they must enter (either via direct loans or incorporated in inter-firm loans) the cost structure as a fixed component ${ }^{16}$. The extent of cross-subsidization is restricted on the basis of leverage bounds $\alpha$ and $\beta$ set at corporate level. With respect to empirical ICMs, the debt-to-equity ratio is critical also outside the realm of purely financial business groups ${ }^{17}$ (see for instance Holod and Peek, 2010) and it is frequently targeted by policy makers. For example, Lee et al. (2009) provide empirical evidence of the effects engendered on Korean conglomerates by an exogenous change in $\alpha$ in the aftermath of Korean 1997 financial crisis. In the following I assume $\beta=1$, corresponding to a lower bound $-\omega \leq I_{\omega}$ and $\alpha \geq 0$. In order to construct a segmentation of firms' behaviour as a function of their cash type, I define the first-best type $\omega \equiv \omega^{* *}$ such as

DEFINITION 2 (First-best type). Let $\omega \equiv \omega^{* *}$ be the first-best type of the economy, defined as

$$
\omega_{p, r}^{* *}: \quad I^{*}\left(\omega_{p, r}^{* *} ; \alpha, r, p\right)=0
$$

Type $\omega_{p, r}^{* *}$ agents make no investment as they are endowed with the first-best liquidity level, independently of the exogenous constraint $\alpha$. Hence, $\omega_{p, r}^{* *}$ rates the profitability of the industry as a function of the optimal unconstrained production level (which depends on the market-wide unit revenue $p$ and $\operatorname{cost} c$ ). When possible, in the following I will drop the subscripts and simply refer to $\omega^{* *}$.

\footnotetext{
${ }^{15}$ The assumption simplify non-essential comparative statics and can be easily relaxed with no effect on any of the main results.

${ }^{16}$ By imposing $c=r$ it is immediate to recover from Assumption 1 the spread structure as described in the empirical literature (see for instance Allen et al., 2019).

${ }^{17}$ Looking at aggregate leverage ratios, Buchuk et al. (2014) find that recipients of intra-group transfers in Chilean business groups have leverage ratios that are $7-10 \%$ higher than non-conglomerated firms.
} 


\subsection{Bank Lending policy $(t=0)$}

My treatment of the bank's lending policy is designed to match some critical empirical regularities in the bank-firm relation and, a novelty, to study how the policy shapes the morphology of the $\mathrm{ICM}^{18}$. In this sense, I expand Freimer and Gordon (1965) classical framework to account for borrowers with heterogeneous endowments. The bank faces an adverse selection problem (Stiglitz and Weiss, 1981 and Smith, 1987) when attempting to ration credit by price. Instead, the bank offers competitive interest rates and ration loans by assets evaluation ${ }^{19}$. I assume that the bank acquires (lends) liquidity at competitive $\operatorname{cost} \tau$ (rate $r$ ). In the first phase of the model, the bank arranges the lending policy $\omega_{e}$, defined as

$$
\omega_{e} \equiv \omega(e ; r, \tau, \chi)=g \cdot e, \quad e \in\{0, \ldots, \bar{e}\}
$$

by optimally selecting the leverage $g \geq 0$ contingent to: $(i)$ the borrower's internal funds $e_{i}$ and $(i i)$ macro-variables $p, c, r$ and technology $f(\cdot)$, that allow the bank to compute the first-best type $\omega_{p, r}^{* *}$. The bank investment is worth $Z_{e} \equiv \min \left\{\chi_{e},(1+r) \omega_{e}\right\}$. The expression implies that conditional on the realization of the project, the bank either realizes the planned profit, or gets an expected amount $\chi_{e}$ after writing off a failed project. Typically, $\chi$ indicates a positive amount of capital defined in terms of a share $\chi$ of the initial endowment $e$, that is a recovery rate or a collateral over the PU's internal funds: $\chi_{e}=\chi \cdot e$ with $\chi \in[0,1]^{20}$. As firms can not commit ex-ante to their sales $p f\left(K_{i}\right), i \in N$ and the bank does not know the internal debt-to-equity ratio $\alpha$ (i.e, the extent of inter-firm funding), the bank computes the expected proceeds of her own investment $Z_{e}$ according to an estimate over the range of possible sales. To do so, the bank uses a simple rectangular distribution $\rho(e)$ given by

$$
\rho(e) \equiv \begin{cases}\frac{1}{p f\left(\omega^{* *}\right)-e} & \text { for } p f\left(\omega^{* *}\right)-e>1 \\ 1 & \text { otherwise }\end{cases}
$$

\footnotetext{
${ }^{18} \mathrm{As}$ the angle of this paper is to isolate the contribution of a trickle-down financing mechanism to the formation of ICMs, I deviate from the traditional contract-theoretic framework (such as Gertner et al., 1994) and condense all contract-theoretic concerns in the bank-firm relationship, thus assuming perfect enforcement at the firm-firm relationship.

${ }^{19}$ The rationing proposed here is consistent with the empirical finding of a large literature investigating the nexus between bank rationing and BG performance (see, for example, Gopalan et al., 2007).

${ }^{20}$ Banks and regulators may enforce a tight interpretation of loss given default over a single position. For instance, by netting the collateral from a range of standard expected penalties (such as litigation costs) that become apparent once the project fails, the bank may estimate a $\chi$ within the more eventful interval $[-1,1]$. By analyzing a large sample of small business non-performing bank loans, Eales and Bosworth (1998) provide strong evidence of a convex relation between severity and frequency of loss given default. Relevantly, losses given default exceeding by up to the $20 \%$ of the principal (i.e. $\chi=-0.2$ ) are reported twice the frequency with respect to cases with recovery rates range in $\chi \in[0.7,0.9]$.
} 
so that $Z_{e}$ is distributed according to $\rho$. In the above, risk increases in the distance between endowment $e$ first-best sales, $p f\left(\omega^{* *}\right)^{21}$. Because the bank conditions liquidity provision on the PU's assets, I express $\omega_{e}$ in terms of the implied leverage $g=\frac{\omega_{e}}{e}$. This formulation directly reflects that when a firm borrows against its assets, borrowing capacity depends upon the collateral size. Therefore, the bank maximizes the expected profits over loan provision to $e$-type entrepreneur by adjusting the leverage $g$ given in $g \cdot e$

$$
\max _{g} \mathbb{E}\left[\Pi^{B} \mid e\right]
$$

where $\mathbb{E}\left[\Pi^{B} \mid e\right]$ is equal to

$$
\int_{0}^{g e(1+r)} \chi \cdot e \rho d s+\int_{g e(1+r)}^{p \cdot f\left(\omega^{* *}\right)} g e(1+r) \rho d s-(1+\tau) g e .
$$

The first component reflects the expected outcome in case of firm's default (corresponding to the seized collateral in the standard interpretation of $\chi \in[0,1]$ or a penalty for $\chi<0$ ), net of trade credit exposures. The second component, which is pinned down by the investment profitability is the expected profit conditional on the investment's success. The third component is the cost of capital. Then, I have the following

Proposition 1. Let $A_{p, r, \tau}$ be the flat-base loan and $B_{r, \tau, \chi}$ the type-based discrimination, respectively given by $A_{p, r, \tau} \equiv p \cdot f\left(\omega^{* *}\right) \cdot \frac{(r-\tau)}{2(1+r)^{2}}$ and by $B_{r, \tau, \chi} \equiv \frac{\chi(1+r)+(1+\tau)}{2(1+r)^{2}}$. Let $\Omega \equiv$ $\left\{A_{p, r, \tau}, \ldots, A_{p, r, \tau}+\bar{e} \cdot B_{r, \tau, \chi}\right\}$ be the equilibrium endowment space. Then,

1. A unique optimal lending policy $\omega_{e}=g^{*} e, \forall \omega \in \Omega$ exists and is given by

$$
\omega_{e}= \begin{cases}A_{p, r, \tau}+e \cdot B_{r, \tau, \chi} & \text { for } r \geq \tau \\ 0 & \text { otherwise }\end{cases}
$$

2. Let $\theta$ be the bank's relative cost of liquidity sourcing, defined as $\theta \equiv \frac{1+\tau}{1+r}$, the optimal credit rationing policy is an increasing (decreasing) function of the borrower's type if and only if $\chi>-\theta(\chi<-\theta)$.

3. Let $e_{p, r, \tau}^{*}$ as defined in (B.1) (Appendix B). For all endowment $e<e_{p, r, \tau}^{*}$ (respectively, $e \geq e_{p, r, \tau}^{*}$ ), the optimal credit rationing policy $\omega$ is an increasing (respectively, decreasing) function of the bank rate $r$. Furthermore, for $\theta<1 / 2$, there exists $\bar{p}_{\theta}>0$ such that for $p>\bar{p}_{\theta}$, it holds that $e_{p, r, \tau}^{*}<0$ and the optimal credit rationing policy $\omega$ is a decreasing function of $r$.

4. Let $\hat{e}_{p, r} \equiv p f\left(\omega^{* *}\right)$ be the pivotal type and consider money market costs $\tau_{1}, \tau_{2}$ such that $\tau_{2}>\tau_{1}>0$. It holds that $\omega\left(e^{\prime} ; \tau_{2}\right)>\omega\left(e^{\prime} ; \tau_{1}\right)$ (respectively, $\left.\omega\left(e^{\prime} ; \tau_{2}\right)<\omega\left(e^{\prime} ; \tau_{1}\right)\right)$ for $e^{\prime}>\hat{e}_{p, r}$ (respectively, $\left.e^{\prime}<\hat{e}_{p, r}\right)$.

\footnotetext{
${ }^{21}$ This simple risk structure instruments the potential firm's operational risk (see Freimer and Gordon, 1965 ) with a bound on the firm's return on asset (ROA). In the model, operations are simply given by input transformation and marketing of output.
} 
5. Cash endowment $\omega$ is distributed according to the uniform equilibrium distribution $p_{\omega}$, defined as

$$
p_{\omega} \equiv \mathcal{U}\left\{A_{p, r, \tau}, A_{p, r, \tau}+\bar{e} \cdot B_{r, \tau, \chi}\right\}=\frac{1}{\bar{e} B_{r, \tau, \chi}},
$$

for $\omega \in \Omega$ and $p_{\omega}=0$ otherwise. From (6) is immediate to define $P_{\omega}$ as the CDF associated to $p_{\omega}$.

When lending rate is at least enough to cover the money market cost (i.e. $r \geq \tau$ ), the optimal lending in (5) is a proportional two-parts scheme. The first component is a flat-base loan which incorporates the net profitability of production discounted for the bank credit costs. The second component is a type-specific premium added on the top of the base loan. I briefly discuss the equilibrium behaviour of $p_{\omega}$ in relation to each of the macro-variables by making use of the criterion of First Order Stochastic Dominance $(\mathrm{FOSD})^{22}$

- Improvement of production market's profitability. Since $B$ is non affected by $p, p$ induces a linear right-shift of the support $\Omega$ via $A$, thus implying that when the market price $p$ grows, the bank uniformly raises loans to all borrower types $e$. In terms of distribution properties, $p_{\omega}^{\prime}\left(p^{\prime}\right) \stackrel{\text { FO }}{\succ} p_{\omega}(p)$ for $p^{\prime}>p$.

- Increment of bank's interest rate. Two cases are possible, depending on the composition of $\Omega$. If $e_{p, r, \tau}^{*}<0$ (equivalent to $\theta<1 / 2$ and $p>\bar{p}_{\theta}$ ) a hike of the bank's interest rate reduces both $A$ and $B$ (that is $\Omega$ shrinks), and as such, $p_{\omega}(r) \stackrel{\text { FO }}{\succ} p_{\omega}^{\prime}\left(r^{\prime}\right)$ for $r^{\prime}>r$. Otherwise, if $e_{p, r, \tau}^{*}>0$ a result in terms of distribution's dominance can not be established as lending behaviour will be endowment-specific.

- Increment of money market's cost. An increment of bank's financing cost $\tau$ reduces $A$ and makes $B$ steeper, so that when money markets become more expensive, the bank discriminates more intensively between borrowers, with the result of increasing (respectively, reducing) credit available for large (respectively, small) firms such that $e \geq \hat{e}_{p, r}$ (respectively, $e<\hat{e}_{p, r}$ ).

- Increase of recovery rate. An increment of $\chi$ implies a positive shift of $B$ with a neutral effect on $A$, which translates in the expansion of $\Omega$, and in terms of the distribution, it implies that $p_{\omega}^{\prime}\left(\chi^{\prime}\right) \stackrel{\text { FO }}{\succ} p_{\omega}(\chi)$ for $\chi^{\prime}>\chi$. Therefore, when the bank's recovery rate improves, the bank unambiguously extends credit lines to all types $e$.

\footnotetext{
${ }^{22}$ Given two univariate distributions $p_{\omega}$ and $p_{\omega}^{\prime}, p_{\omega}$ First Order Stochastic Dominates $p_{\omega}^{\prime}$ or, equivalently, $p_{\omega} \stackrel{\text { FO }}{\succ} p_{\omega}^{\prime}$ if $p_{\omega} \leq p_{\omega}^{\prime} \forall \omega \in \Omega$. This is to say that the mass of the distribution moves upward on the support when the distribution shifts from $p_{\omega}^{\prime}$ to $p_{\omega}$.
} 


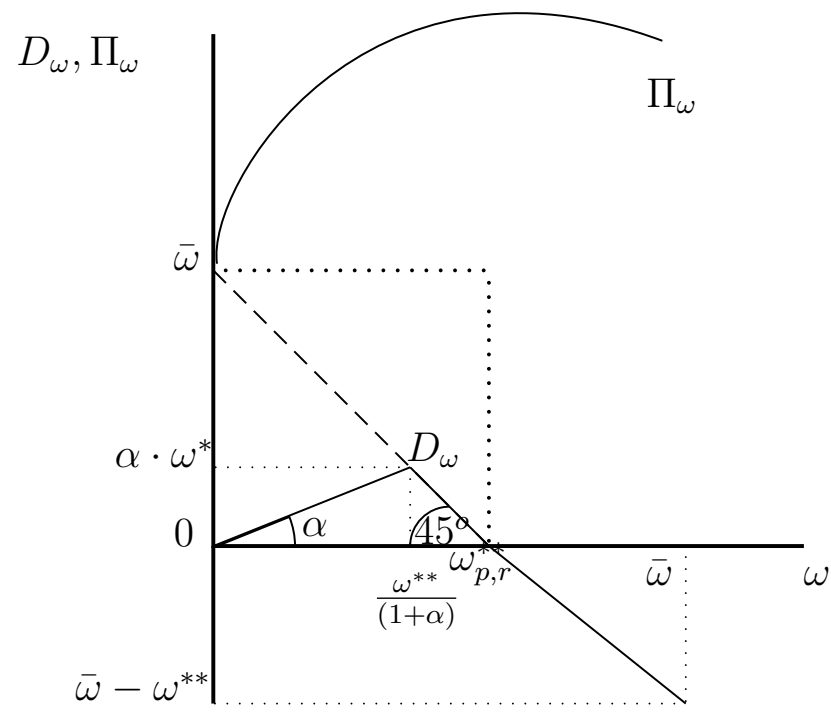

Figure 2: The market segmentation for a given $\alpha>0$ and $\omega^{* *}<\bar{\omega}$. Given the profit function $\Pi_{\omega}$ in (1), types are segmented via $D_{\omega}$ as obtained in Proposition 2.

\subsection{The Demand Structure of ICM $(t=0)$}

At $t=0$, given the bank's optimal lending policy $\omega_{e}$, each PU $i \in N$ receives $\omega_{e_{i}}$ and induces the following type-based demand for cash $D_{i}=D_{\omega_{i}}=D_{\omega} \geq 0$ (for convenience I drop the firm's identifier)

$$
D_{\omega} \equiv\left\{\begin{array}{ll}
I_{\omega}^{*} & \text { if } I_{\omega}^{*} \geq 0 \\
0 & \text { otherwise }
\end{array} .\right.
$$

I characterize the demand segmentation at type level $D_{\omega}$ as a function of $\omega_{p, r}^{* *}$ and $\alpha$ and provide a necessary aggregate condition for the emergence of the capital market.

Proposition 2 (Market Segmentation). (i) For each $\omega \in \Omega$, the constraint $\alpha$ and the first-best type $\omega^{* *}(p, r)$, the continuous function $D_{\omega}: \Omega \rightarrow \Omega$ maps each type in its own demand for capital such as:

$$
D_{\omega}= \begin{cases}\alpha \cdot \omega & \forall \omega \in D^{*} \\ \omega^{* *}-\omega & \forall \omega \in D^{* *} \\ 0 & \forall \omega \in S\end{cases}
$$

with: $D^{*} \equiv\left\{\omega \in \Omega: \omega \leq \omega^{* *} /(1+\alpha)\right\}, D^{* *} \equiv\left\{\omega \in \Omega: \omega^{* *} /(1+\alpha) \leq \omega<\omega^{* *}\right\}, S \equiv$ $\left\{\omega \in \Omega: \omega \geq \omega^{* *}\right\}$.

(ii) The average demand for capital $D\left(\alpha, \omega^{* *}\right)=D^{*}+D^{* *}$ is given by the quantity

$$
D\left(\alpha, \omega^{* *}\right)=p_{\omega}\left(\frac{\alpha}{1+\alpha} \frac{\left(\omega^{* *}\right)^{2}}{2} \cdot \frac{1}{\bar{\omega}}\right),
$$

(iii) $D\left(\alpha, \omega^{* *}\right)$ is concave with respect to $\alpha$ and convex with respect to $\omega_{p, r}^{* *}$. 
Importantly, $D_{\omega}$ defines the quantity of capital with which every PU type aims to settle in the market as a (static) function of the bank lending policy and the debt-to-equity regulations. PU of type $\omega \in D^{*}$ (respectively, $\omega \in D^{* *}$ ) are fully (respectively, partially) constrained borrowers, that is they will borrow at capacity (respectively, up to match first best endowment $\omega_{p, r}^{* *}$ ) from other PUs. Firms of type $\omega \in S$ on the other hand will enter the ICM with zero demand for capital, $D_{\omega}=0$, and we will refer to firms belonging to $S$ as non-borrowers or, alternatively, as pure lenders. For convenience, I also define

$$
K_{\omega} \equiv \omega+D_{\omega}
$$

such as the cash holdings of a PUs, that is the cash a PU settles in the ICM with as potential lender for next periods PUs.

\subsection{Intra-group exchange incentives ( $t>0$ )}

Consider a generic period $t>0$ such that $t<\bar{t}$ and fix $\left(t, t^{\prime}\right)$ to be a match between $t$ and $t^{\prime}$, where $t$ is the newcomer characterized by a (possibly null) demand for cash $D_{t}=D_{\omega_{t}}$ and $t^{\prime}$ is a generic lender $t^{\prime} \in N_{t-1}$, with $t^{\prime}<t$. In this subsection I hold the match as fixed and introduce the incentive structure of capital transfer from $t^{\prime}$ to $t$. In the next section I will look in detail at the matching process and the dynamics of ICM.

At time $t$, the lender is characterized by a cash endowment $K_{t^{\prime}}(t) \geq 0$ and outstanding loans $\bar{s}_{t^{\prime}}(t-1) \geq 0$ (See Definition 1 ), which I keep fixed in this section. I leverage Assumption 2.2 to characterize pairwise capital flow from $t^{\prime}$ to $t$. I assume this is given by exchange of cash loan $\ell_{t t^{\prime}}>0$ against an "interest rate" $\iota_{t t^{\prime}}>0$, which will be computed against the lender's most obvious outside option, that is the employment of the resources for direct production ${ }^{23}$. Coherent with a founding empirical regularity ${ }^{24}$ of the financing motive for ICMs existence (Buchuk et al., 2014), for transactions to be incentive compatible it is necessarily that the interest rate is at least sufficient to cover the lender's ongoing projects. Therefore, I introduce an exchange incentive compatibility condition. The condition restricts the set of feasible exchanges to pairwise efficient combinations of cash loans $\ell_{t t^{\prime}}$ and loan interest rate $\iota_{t t^{\prime}}$.

\footnotetext{
${ }^{23}$ Notice that it is such incentive structure that opens up an interesting arbitrage opportunity where borrower $t \in N_{t}$ becomes a potential lender for borrower $t^{\prime \prime}>t$ accessing the ICM in next periods, thus effectively spreading the bank's capital through the ICM, coherently with a pervasive empirical regularity of ICMs (see, for example, Buchuk et al., 2014 and Almeida et al., 2011), where capital trickles-down from larger and more mature low-productivity firms to younger and smaller high-productivity firms.

${ }^{24}$ Gopalan et al. (2007) show that interest rates charged by lenders can have only a latent connection with those of formal money market in Indian Business groups. By looking at Chinese entrusted loans, official interest rates act as a further lower bound (Allen et al., 2019). A mechanism based upon exchange of liquidity against internal equity would prioritize strategic incentives rather than financing incentives behind the ICM. It is unclear which motif is predominant (see Buchuk et al. (2014) for a discussion ). Furthermore, the second mechanism would put a strong assumption on the direction of capital flows.
} 


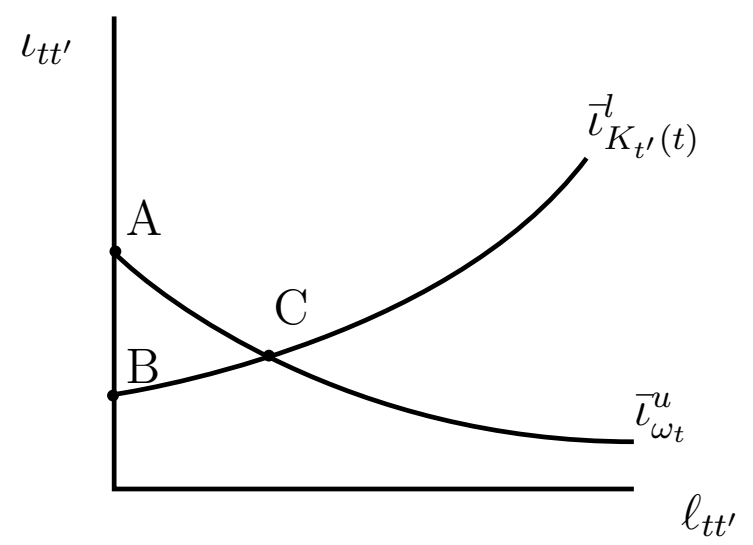

Figure 3: The space of incentive-compatible exchanges between a newcomer $t$ and a potential lender $t^{\prime}$, respectively endowed with $\omega_{t}$ and $K_{t^{\prime}}(t)$, as obtained from Assumption 4 is given by area $A B C$. In the graph, production function $f(K)$ is logarithmic. On the x-axis: loan size $\ell_{t t^{\prime}}, \mathrm{y}$-axis: boundaries $\bar{\iota}_{t^{\prime}}^{l}$ and $\bar{\iota}_{t}^{u}$ on interest rate $\iota_{t t^{\prime}}$.

ASSUMPTION 4 (Incentive Compatibility of Exchanges). Given a lender (respectively, the newcomer) $t^{\prime} \in N_{t-1}$ endowed at $t$ with $K_{t^{\prime}}(t)$ (respectively, $\left.\omega_{t}\right)$, with $t^{\prime}<t$, a loan $\ell_{t t^{\prime}}$ at interest rate $\iota_{t t^{\prime}}$ has to be incentive compatible to take place, whereby incentive compatibility requires that

$$
\begin{gathered}
\ell_{t t^{\prime}} \in\left[0, K_{t^{\prime}}(t)\right] \\
\iota_{t t^{\prime}} \in\left[\vec{\iota}_{K_{t^{\prime}}(t)}, \bar{\iota}_{\omega_{t}}^{u}\right],
\end{gathered}
$$

in which

$$
\vec{\iota}_{K_{t^{\prime}}(t)} \equiv \frac{p\left[f\left(K_{t^{\prime}}(t)\right)-f\left(K_{t^{\prime}}(t)-\ell_{t t^{\prime}}\right)\right]}{\ell_{t t^{\prime}}}+r, \quad \bar{\iota}_{\omega_{t}}^{u} \equiv \frac{p\left[f\left(\omega_{t}+\ell_{t t^{\prime}}\right)-f\left(\omega_{t}\right)\right]}{\ell_{t t^{\prime}}}-r .
$$

To motivate the above, observe that the exchange is incentive compatible for lender $t^{\prime}$ if

$$
p \cdot f\left(K_{t^{\prime}}(t)-\ell_{t t^{\prime}}\right)+\iota_{t t^{\prime}} \ell_{t t^{\prime}}-r\left(K_{t^{\prime}}(t)-\ell_{t t^{\prime}}\right) \geq p \cdot f\left(K_{t^{\prime}}(t)\right)-r \cdot K_{t^{\prime}}(t),
$$

in which the right hand side is the opportunity cost and $\iota=\bar{\iota}_{K_{t^{\prime}}(t)}$ equalizes the inequality. The bound $\vec{\iota}_{\omega_{t}}^{u}$ is symmetrically obtained for the borrower $t$. For any transfer $\ell_{t t^{\prime}}$, the assumption provides necessary conditions on terms of trade for a bilateral trade to take place. These conditions map directly into each party's endowment $\omega_{t}, K_{t^{\prime}}(t)$, which in turn depends on bank loans and the residual cash retained by potential lenders $t^{\prime} \in N_{t-1}$ for direct production (formally defined in Section 2.7). To simplify the exchange structure, I further assume the following

ASSUMPTION 5 (Size of loans are fixed). For every matching $\left(t, t^{\prime}\right), t, t^{\prime} \in N$, assume that the size of loans is fixed, $\ell_{t t^{\prime}}=\ell, \ell>0$ so that every matched couple $\left(t, t^{\prime}\right)$ bargains only over the interest rate $\iota_{t t^{\prime}}$.

The dimension of the window of jointly acceptable rates expands in the lender's availability of funds. I assume that borrowers order lenders according to a measure of attractive- 
ness which is determined by the spread between the maximum interest rate payable by the borrower and the minimum interest rate acceptable for the lender. Hence, for each matched pair $\left(t, t^{\prime}\right)$, define attractiveness of lender as follows

DEFINITION 3 (Attractiveness of Lender). Let a matched pair $\left(t, t^{\prime}\right)$ respectively endowed with cash $\omega_{t}$ and $K_{t^{\prime}}(t)$. Then, define $\Gamma_{t^{\prime}}\left(\omega_{t}, K_{t^{\prime}}(t)\right)$ such as

$$
\Gamma_{t^{\prime}}\left(\omega_{t}, K_{t^{\prime}}(t)\right) \equiv \frac{\bar{\iota}_{\omega_{t}}^{u}}{\bar{\iota}_{K_{t^{\prime}}(t)}^{l}}
$$

The attractiveness function is convex and increasing in the endowments of the lender and convex and decreasing in the endowment of the borrower. I use the notion in Section 2.7 as the main element of PUs' exchange protocol.

\subsection{Exchange Dynamics and Formation of ICMs $(t>0)$}

Consider again a generic period $t>0$. In this section, I characterize the dynamics of ICMs. To do so, I first build the law of motion of loanable funds for any generic lender $t^{\prime} \in N_{t-1}$. From Assumption 5, it follows that $\bar{s}_{t^{\prime}}(t-1)=\ell \cdot s_{t^{\prime}}(t-1)$, where $s_{t^{\prime}}(t-1) \geq 0$ is the number of loans supplied by lender $t^{\prime}$ along the time interval $\left|t-t^{\prime}\right|$. Then, loanable funds are simply given by

$$
\underbrace{K_{t^{\prime}}(t)}_{\text {loanable funds }}=\underbrace{\omega_{t^{\prime}}+D_{t^{\prime}}}_{\text {initial cash holdings }}-\underbrace{s_{t^{\prime}}(t-1) \cdot \ell}_{\text {loaned cash }}
$$

in which it holds that ${ }^{25} K_{t^{\prime}}\left(t^{\prime}\right)=\omega_{t^{\prime}}+D_{t^{\prime}}=K_{\omega_{t^{\prime}}}$. Furthermore, budget constrain limits inter-firm exposure such that $K_{t^{\prime}}(t) \geq 0 \forall t \geq 0$.

Next I characterize the dynamics of exchanges across periods. ICMs are unregulated markets in which PUs come to idiosyncratic pairwise arrangements, hence the menu of available contracts can be very sparse (see, e.g., Khanna and Palepu, 2000 and Khanna and Yafeh, 2007). Therefore, I introduce a probabilistic exchange protocol to allow for a broad spectrum of unobservable and noisy contracts. Formally, in the following I construct a probability $\xi_{t^{\prime}}(t)$ of exchanges between a newcomer $t$ and potential lender $t^{\prime} \in N_{t-1}$. This is given by the following

DEFINITION 4 (Exchange probability). Given a mature firm $t^{\prime} \in N_{t-1}$ endowed with $K_{t^{\prime}}(t)$ and a newcomer $t$, let $\xi_{t^{\prime}}(t)$ be the probability of an exchange of capital $\ell$ to take place from $t^{\prime}$ to $t$, and define it as

$$
\xi_{t^{\prime}}^{\prime}(t) \equiv \begin{cases}P\left(\mathrm{t} \text { is matched with } t^{\prime}\right) \cdot P\left(\text { trade realizes } \mid D_{\omega_{t}}, K_{t^{\prime}}(t)\right) & \text { for } K_{t^{\prime}}(t)>0 \\ 0 & \text { otherwise }\end{cases}
$$

\footnotetext{
${ }^{25}$ Importantly, the evolution of $s_{t^{\prime}}(t) \geq 0$ will proxy the analysis of ICM formation in Section 3.
} 
I now introduce three assumptions to produce a tractable expression for $\xi_{t^{\prime}}(t)$. First,

ASSUMPTION 6. Given a newcomer $t$ and two potential lenders $t^{\prime}, t^{\prime \prime} \in N_{t-1}$, the probability $\xi(\cdot)$ is increasing in the lender's attractiveness. In other words, $\xi_{t^{\prime \prime}}(t)<\xi_{t^{\prime}}(t)$ if and only if $\Gamma_{t^{\prime \prime}}\left(\omega_{t}, K_{t^{\prime \prime}}(t)\right)<\Gamma_{t^{\prime}}\left(\omega_{t}, K_{t^{\prime}}(t)\right)$, in which $K_{t^{\prime}}(t)$ and $K_{t^{\prime \prime}}(t)$ follow the law of motion in (14).

Assumption 6 is actually weak. It captures the empirical (and possibly noisy) counterpart of pairwise efficiency: irrespective of the actual distribution of the exchange surplus and for any postulated bargaining mechanism, matched parties (or their parent entity) prefer to trade with a counterpart for which the measure of attractiveness in (13) is wider, as the higher the probability the financial exchange is pareto-improving, the more likely is to take place. The mechanism is coherent with the findings of Almeida et al. (2015), which show that in Korean ICMs liquidity goes from low-productivity firms to highproductivity firms and transfers are pairwise incentive compatible. Given the incentive structure in Section 2.6, I make two observations. First, the attractiveness of a lender $t^{\prime} \in N_{t-1}$ depends on her own endowments $K_{t^{\prime}}(t)$, on the borrower's type $\omega_{t}$ and also on the amount of capital $x \leq D_{\omega_{t}}$ that the borrower collected on market before being matched to $t^{\prime}$. At the same time, the maximum gains that a borrower $t$ (or, equivalently, her controlling entity) can make out of $\ell$ by using it in production is fixed and only depends on the market structure. This allows to define the average attractiveness of a lender $t^{\prime}$ (respectively, of the ICM) such as

DEFINITION 5 (Average Attractiveness of a Lender and of ICM). Let $t^{\prime} \in N_{t-1}$ endowed with residual cash $K_{t^{\prime}}(t)$ at $t>t^{\prime}$. Then, the average attractiveness of $t^{\prime}$ is defined as

$$
\gamma\left(K_{t^{\prime}}(t)\right) \equiv \int_{0}^{\omega^{* *}} \int_{0}^{\left(D_{\omega}-\ell\right)}\left(\Gamma_{t^{\prime}}\left(x, \omega, K_{t^{\prime}}(t)\right) \cdot p_{\omega}\right) d x d \omega
$$

Furthermore, let the average profitability of the ICM be defined as

$$
\phi_{r, \tau, \chi, \alpha, \omega^{* *}} \equiv \int_{0}^{\omega^{* *}} \int_{0}^{\left(D_{\omega}-\ell\right)}\left(\bar{\iota}_{\omega}^{u}(x, \omega) \cdot p_{\omega}\right) d x d \omega
$$

Hence, $\gamma\left(K_{t^{\prime}}(t)\right)$ averages the attractiveness of a lender $t^{\prime}$ across all possible types of newcomers $\omega \in D \subset \Omega$ that already collected an amount $x<D_{\omega}$ of liquidity target $D_{\omega}$ along the intra-period search. On the other hand, $\phi$ evaluates on average the maximum gains that a newcomer $\omega$ (or, equivalently, her controlling entity) can make out of $\ell$ in the production market, given any level of capital she may have already raised in the ICM and any initial endowment. By providing a metrics for the potential gains that come from a transaction - regardless to their assignation between the borrower and lender - $\phi$ measures the welfare incentives to participate to ICMs for single PUs. Second, I assume the following 
ASSUMPTION 7. The matching process is random.

For large $t$, the probability for a borrower to be matched with a lender dissolves into $1 / t$. On average it must be that

$$
\xi_{t^{\prime}}(t) \approx \frac{1}{t} \cdot \gamma\left(K_{t^{\prime}}(t)\right)
$$

Given the exchange incentives and the current size of the ICM, two equally appealing lenders have the same probability of being matched to a newcomer. This simple matching assumption provides a departure from optimality of ICM capital allocation (Nicodano and Regis, 2019, Shin and Park, 1999) which is moderated by the fact that the exchange probability expands in the lender's availability of funds and in all cases, exchanges have to be pairwise efficient to realize. Lastly, I assume that

ASSUMPTION 8. Lender's financial exposure is allowed to grow unboundedly in (14).

In other words, $K_{t^{\prime}}(t)$ is unbounded. A priori, the approximation appears at odds with the inter-firm exchange structure (Section 2.6), where firms' endowments drive exchange incentives. However, I moderate the assumption by exploiting Assumption 5 and approximate

$$
\iota_{K_{t^{\prime}}(t)} \approx m\left(\omega_{t^{\prime}}\right) \cdot s_{t^{\prime}}(t-1) \cdot \ell
$$

in which

$$
\left.m\left(\omega_{t^{\prime}}\right) \equiv \frac{d \bar{\iota}_{K_{t^{\prime}}\left(t^{\prime}\right)}^{l}}{d \ell}\right|_{s_{t^{\prime}}=0}
$$

is a first order approximation fixing the increment in marginal productivity caused by the reduction of residual capital $K_{t^{\prime}}(t)$ as lender $t^{\prime}$ increases exposure against other PUs. Hence, the attractiveness of $t^{\prime}$ is thus affected by her own type, the quantity of capital she raises before settling in the market and the number of loans she already issued in the market. Therefore, absent a formal budget constraint, the exchange probability retains the ordering structure of Section 2.6. Nonetheless, it is possible that the qualitative properties of the stationary inter-firm lending distributions derived in Section 3 are impinged by Assumption 8. To assess the robustness of my results, in Appendix A I notice that the introduction of a budget constraint may be interpreted as a truncation of the distributions. Therefore, in Proposition 10 I show that one of the main results derived in Section 3 is robust to any truncation ${ }^{26}$. A similar argument applies to all other analytical

\footnotetext{
${ }^{26}$ Furthermore, in Section 4.1 I confirm in simulations the validity of the assumptions made in this section.
} 
results of Section $3^{27}$. Given the assumptions, $\xi_{t^{\prime}}(t)$ becomes

$$
\xi_{t^{\prime}}(t)=\frac{\phi_{r, \tau, \chi, \alpha, \omega^{* *}}}{t \cdot m\left(\omega_{t^{\prime}}\right) \cdot s_{t^{\prime}}(t-1) \cdot \ell}
$$

Notice that the denominator of $\xi_{t^{\prime}}(t)$ indicates the current productivity of $t^{\prime}$ and it entirely depends on $t^{\prime}$ characteristics and her investment decisions.

\section{Analysis}

\subsection{Stationary $I C M s$}

In this paper, the dynamic ICM is studied in terms of the evolution of inter-PU crosssubsidization, that is the lending side of the ICM. Hence, the evolution of the exchange protocol $\xi_{t^{\prime}}(t)$ drives the formation of ICM. The probability $\xi_{t^{\prime}}(t)$ rests on the determination of cash loans $s_{t^{\prime}}(t)$. However, the complexity of tracking the granular evolution of $s_{t^{\prime}}(t)$ along the entire formation path $t^{\prime}, t^{\prime}+1, \ldots$ rapidly grows to intractable dimensions since it is a function on the decision of all firms in the ICM. To overcome the high degree of complexity regulating the above law of motion, I take as unit of analysis for the dynamical ICM the following

DEFINITION 6 (ICM Architecture). Given types $\omega \in \Omega$ and $s \geq 0$, and given the exchange probability in (18), let $t \rightarrow \infty$ and define $P(s, \omega)$ such as the probability distribution of inter-firm loans $s$ and types $\omega \in \Omega$. I refer to $P(s, \omega)$ as the ICM architecture of the model.

Importantly, since any ICM drawn from the class $P(s, \omega)$ is equally likely, the result is not conditioned on the identities of the individual firms: the ICM architecture is anonymous in the sense that it maps in a frequency each combination of firm's type and total number of loans issued in the $\mathrm{ICM}^{28}$. I address the high degree of randomness involved with the determination of $P(s, \omega)$ by adopting a mean-field approximation (see for instance Bramoullé et al., 2012). In the mean-field approximation, all trading actions take place deterministically at a rate proportional to the expected change. On that ground, I will ascertain the properties of the emerging architectures in the limit of $t \rightarrow \infty$. I proceed to the core Theorem of the paper which grounds the rest of the analysis.

Theorem 1 (Existence and Uniqueness of ICM architecture). Given the probability defined in (18) and a market structure $(p, c, \alpha, \beta, r, \tau, \chi)$, there exists a unique ICM archi-

\footnotetext{
${ }^{27}$ Furthermore, out of the present model where external finance is placed ex-ante the ICM formation, the approximation in (17) appears to be reasonable under the empirical observation that firms can go through several rounds of external financing (Khanna and Yafeh, 2007). Hence, a model with dynamical bank re-financing would allow to organically incorporate the Assumption.

${ }^{28}$ Hence, the distribution-based approach avoids an analysis based upon ad hoc ICMs structures, and as such can be tested against data.
} 
tecture $P(s, \omega)$, given by

$$
P(s, \omega)=\frac{\omega-A_{p, r, \tau}}{\bar{e} B_{r, \tau, \chi}} \cdot\left(1-e^{-\frac{m(\omega) \ell \cdot s^{2}}{2 \phi_{r, \tau, \chi, \alpha, \omega^{* *}}}}\right),
$$

for $\omega \in \Omega$ and $P(s, \omega)=0$ for $\omega<A_{p, r, \tau}$ and $P(s, \omega)=1$ for $\omega \geq A_{p, r, \tau}+\bar{e} B_{r, \tau, \chi}$. The associated density $p(s, \omega)$ is given by

$$
p(s, \omega)=\frac{1}{\bar{e} B_{r, \tau, \chi}} \cdot \frac{m(\omega) \ell \cdot s}{\phi_{r, \tau, \chi, \alpha, \omega^{* *}}} \cdot e^{-\frac{m(\omega) \ell \cdot s^{2}}{2 \phi_{r, \tau, \chi, \alpha, \omega^{* *}}}},
$$

for $\omega \in \Omega$ and $p(s, \omega)=0$ for $\omega \notin \Omega$. In the above, $\phi$ is the market profitability as defined in (16) and $A_{p, r, \tau}$ and $B_{r, \tau, \chi}$ are as defined in Proposition 1.

The distribution $P(s, \omega)$ characterizes the lending side of the ICM and depends only on the market structure and on the size of the loans. Therefore, even though the economy in our framework is highly dynamic and non-stationary due to the growing pool of firms and their underlying financial ramifications, I am able to obtain a stationary distribution $P(s, \omega)$ which provides a testable benchmark for measuring the impact of regulations and macro-economic shocks at firm's type $\omega$ level. I can now discuss some general properties of the ICMs and map them to the extant literature.

\subsection{Size of PU bank loans and Intensity of Cross-subsidization}

Preliminary to the analysis, I show that stationary ICM architectures as derived in Section 3.1 conform to a structural regularity of observed ICMs: liquidity provision is asymmetric in ICM. Liquidity goes from low-productivity (larger) firms to high-productivity (smaller) firms (see Buchuk et al., 2014, Almeida et al., 2015, Gilchrist and Zakrajšek, 1998 ). In other words, the trickle-down mechanism introduced in this paper can provide substantial ground for observed ICMs dynamics at pairwise level. I summarize this in the following,

Proposition 3. Given a market structure $(p, \alpha, r, \tau, \chi)$ and $\omega^{\prime}, \omega^{\prime \prime} \in \Omega$ with $\omega^{\prime \prime}<\omega^{\prime}$, for any given ICM architecture $P(s, \omega)$, it holds that $P\left(s, \omega^{\prime}\right)$ first-order stochastic dominates (FOSD) $P\left(s, \omega^{\prime \prime}\right)$, or in other words, $P\left(s, \omega^{\prime}\right) \stackrel{F O}{\succ} P\left(s, \omega^{\prime \prime}\right)$

Hence, there exists an unambiguous and positive relation between the number of loans provided by a firm and her initial cash endowment $\omega$. This is important because it implies that pairwise exchange incentives are sufficiently strong to survive -at distribution levelAssumption 8, where I let firms' budget $K_{t^{\prime}}(t)$ to grow unbounded. 


\subsection{Effect of Debt-to-Equity on Cross-Subsidization}

A large empirical literature posits that ICMs exist due to a frictional problem. Several papers provide evidence of a positive relation between looser internal debt-to-equity constrains and capital relocation, as measured in terms of density of financial ramifications (see, for example, Lee et al., 2009 and Shi et al., 2019). I explore such nexus by assuming a positive shock on the debt-to-equity regulations, allowing corporate leverage to change from $\alpha_{1}$ to $\alpha_{2}, \alpha_{2}>\alpha_{1}$. Such shocks bears two implications. First, the segmentation structure obtained in Proposition 2 shifts on the right. To see this, consider the set of fully (respectively, partially constrained) firms $D^{*}$ (respectively, $D^{* *}$ ). Indeed, it holds that $D_{\alpha_{2}}^{*} \subset D_{\alpha_{1}}^{*} \subset D$ and $\omega_{1}^{*} \equiv \omega^{* *} /\left(1+\alpha_{1}\right)>\omega_{2}^{*} \equiv \omega^{* *} /\left(1+\alpha_{2}\right)$. From Proposition 2 capital demand is a concave function of $\alpha$, thus the shift leads to an aggregate increase on the demand side of the ICM.

Second, the laxer regulation $\alpha$ also effects the other side of the market. Albeit the quantity supplied by type $\omega \in S$ is unaffected (as determined by $\omega_{p, r}^{* *}$ ), there are two orders of effects to consider on $\Omega$ : $(i)$ the interval of fully-constrained borrower types $D^{*}$ shrinks and, as a result, there is more residual capital available in the market that can be freed for lending via to the trickle-down mechanism. (ii) From the lenders' perspective, the average attractiveness of a loan as defined in $\phi_{r, \tau, \chi, \alpha, \omega^{* *}}$ changes, thus affecting the overall interconnectedness of the ICM. I verify that looser regulations $\alpha$ expands inter-firm lending. To do so, I verify the following conditions: (1) Lenders' profits are increasing in the number of loans $s$ they provide on the market. (ii) The number of loans agreed in the system increases with $\alpha$ raising. While the first observation follows directly from pairwise efficiency of exchanges, the second one requires to prove that there exists an unambiguous and positive relation between the ICM structure $P(s, \omega)$ and $\alpha$. To do so, I first isolate a monotonic and positive relationship between $\phi_{r, \tau, \chi, \alpha, \omega^{* *}}$ and $\alpha$. Secondly, I use the criterion of FOSD to order the efficiency of ICMs characterized by different debt-to-equity regulations. Hence,

Proposition 4. (i) Given a market structure and a lending policy $\omega_{e}$, it holds that ICM profitability is bounded between zero and the average profit that a non-fully constrained borrower can make out of her loans by direct production, that is

$$
0 \leq \phi_{r, \tau, \chi, \alpha, \omega^{* *}} \leq \frac{1}{\bar{e} B_{r, \tau, \chi}}\left(\omega^{* *} p f\left(\omega^{* *}\right)-\int_{0}^{\omega^{* *}} p f(\omega) d \omega-r \frac{\left(\omega^{* *}\right)^{2}}{2}\right)
$$

(ii) The average profitability of the ICM $\phi_{r, \tau, \chi, \alpha, \omega^{* *}}$ is increasing and non-negative in $\alpha \geq 0$.

From Proposition 4 profitability is negatively affected by regulations via loss of production revenue due to the reduced capability of firms to obtain capital from the internal market. Because $\phi_{r, \tau, \chi, \alpha, \omega^{* *}}$ measures the potential gains of a transaction - regardless to 
the benefiting party - a reduction of $\phi_{r, \tau, \chi, \alpha, \omega^{* *}}$ decreases the ICM internal welfare. Next, I use again the concept of $\mathrm{FOSD}^{29}$ to show that

Proposition 5. Given two ICM architectures $P(s, \omega ; \alpha)$ and $P^{\prime}\left(s, \omega ; \alpha^{\prime}\right)$ as defined in Theorem 1 with $\alpha \geq \alpha^{\prime}$, then it holds that $P(s, \omega ; \alpha)$ first-order stochastic dominates (FOSD) $P\left(s, \omega ; \alpha^{\prime}\right)$, or in other words, $P(s, \omega ; \alpha) \stackrel{F O}{\succ} P\left(s, \omega ; \alpha^{\prime}\right), \forall \omega \in \Omega$.

In other words, debt-to-equity regulations affect unambiguously the density of the ICM via $\phi_{r, \tau, \chi, \alpha, \omega^{* *}}$. In particular, higher debt-to-equity induces higher cross-subsidization. This monotonic result reasons well with the unanimous empirical evidence mentioned above.

\subsection{Effect of Production Market Profitability on Cross-Subsidization}

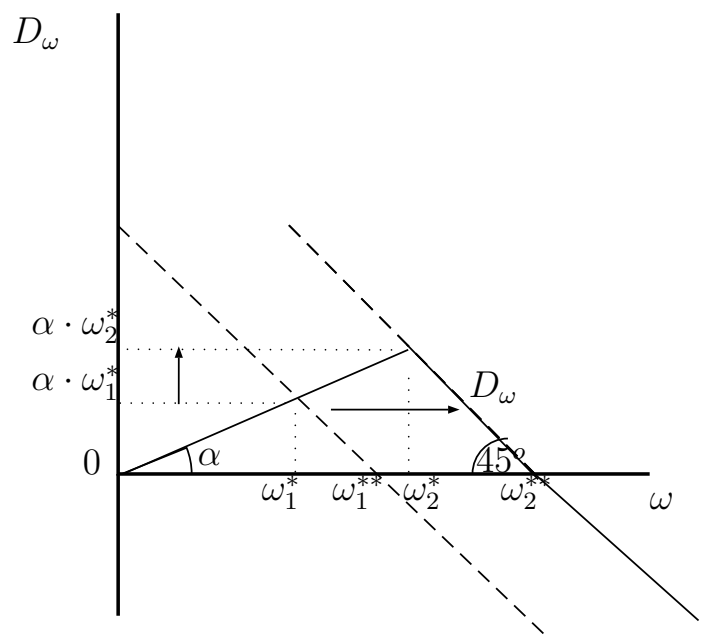

Figure 4: The effect on the demand for inter-firm loans $D_{\omega}$ of an exogenous increase of the market price $p$ from $p_{1}$ to $p_{2}, p_{2}>p_{1}$ for given $\alpha$. The increment translates in a rightward shift of both $\omega_{p, r}^{* *}$ and $\omega^{*} \equiv \omega_{p, r}^{* *} /(1+\alpha)$, respectively from $\omega_{1}^{*}$ to $\omega_{2}^{*}$ and from $\omega_{1}^{* *}$ to $\omega_{2}^{* *}$.

The second dimension shaping the ICM Structure is the good market. A common tenet of the empirical literature on the bright sides of ICM emphasizes the reactivity of ICMs to market shocks (Buchuk et al., 2014). For example, Khanna and Tice (2001) show $^{30}$ that capital allocation within ICMs is highly sensitive to the profitability of local markets, with PUs quickly transferring resources out of deteriorating markets toward growing ones. I explore such channel by letting $p$ shift from $p_{1}$ to $p_{2}, p_{2}>p_{1}$, reflecting an increased profitability of the production market. From (1) and (2) it follows that $\omega_{2}^{* *} \equiv \omega_{p_{1}, r}^{* *} \geq \omega_{1}^{* *} \equiv \omega_{p_{1}, r}^{* *}$ (see also Figure 4). Hence - given the number of firms in the

\footnotetext{
${ }^{29}$ Differently from other works (see Jackson and Rogers (2007)) in which FOSD is assessed for a univariate network distribution $P(s)$, I show that FOSD does hold also in a bivariate case such the one I presented with $P(s, \omega)$. Given two bivariate distribution $P(s, \omega)$ and $P^{\prime}(s, \omega)$, I say that $P(s, \omega)$ first order stochastically dominates $P^{\prime}(s, \omega)$ if $P(s, \omega) \leq P^{\prime}(s, \omega) \forall s>0, \omega \in \Omega$.

${ }^{30}$ I refer the reader to the literature in Khanna and Tice (2001), Khanna and Palepu (2000) and Buchuk et al. (2014) for a comprehensive set of examples.
} 
economy - the segmentation of the ICM will vary according to

$$
\frac{\partial N_{t}}{\partial \omega^{* *}}=\frac{t}{\bar{e} B_{r, \tau, \chi}} \cdot(\underbrace{\frac{1}{1+\alpha}}_{\text {fully-constrained }}+\underbrace{\frac{\alpha}{1+\alpha}}_{\text {partially-constrained }}-\underbrace{1}_{\begin{array}{c}
\text { pure } \\
\text { lenders }
\end{array}})=0 .
$$

Two contrasting effects are potentially in place. A positive shock on attractiveness increases the pressure over capital supply but also shrinks the amount of pure lenders $\omega \in$ $S$ in the system. Hence, I first establish a relation between welfare and ICM connectedness by ordering through FOSD the different geometries induced by changes in $\omega_{p, r}^{* *}$. In the following I characterize the behavior of $\phi_{r, \tau, \chi, \alpha, \omega^{* *}}$ with respect to a change in $\omega_{p, r}^{* *}$

Proposition 6. For $\alpha \geq 0$, the average profitability of a loan $\phi_{r, \tau, \chi, \alpha, \omega^{* *}}$ is bounded below by 0 and is strictly increasing in $\omega_{p, r}^{* *}$.

The above leads to a clear-cut ordering between cross-subsidization and the production market profitability

Proposition 7. Given two ICM architectures $P\left(s, \omega ; p_{1}\right)$ and $P^{\prime}\left(s, \omega ; p_{2}\right)$ as defined in Theorem 1 with $p_{2} \geq p_{1}$, it holds that $P\left(s, \omega ; p_{2}\right) \stackrel{F O}{\succ} P^{\prime}\left(s, \omega ; p_{1}\right)$

The finding in Proposition 7 is indeed supportive of the transfer mechanism described in literature on the bright side of ICMs mentioned at the beginning of the Section, where ICM reacts to better (respectively, worse) market opportunities by increasing (respectively, reducing) inter-firm cross-subsidization.

\subsection{The Interplay Between Internal and External Financing}

Lastly $^{31}$, I address the nodal issue of the interaction between internal and external finance by studying the effect of changes to the cost of money market $\tau$ and bank rate $r$. From Proposition 1, a shock on either channel can be decoupled in two dimensions. First, a common shock in the flat-base loan $A_{p, r, \tau}$ symmetrically affects any type $e \in\{0, \ldots, \bar{e}\}$. At the same time, the bank adjusts the type-specific component of the lending policy given by the type-based discrimination $B_{r, \tau, \chi}$. Hence, at firm level, the net effect on credit availability is type-specific. In principle, At ICM level, the uneven response of bank credit rationing can bear two effects, depending on the shock: first, it may lead to a shift in the concentration of the mass of loans toward higher or lower types. Second, it may contribute in rarefying (respectively, densifying) the overall ICM structure. In addition to these effect, a shock on the bank rate $r$ may alter the exchange and borrowing incentives via a change in the profitability of the production market.

\footnotetext{
${ }^{31}$ I thank an anonymous referee for critical suggestions that led to the results of this section.
} 


\subsubsection{Shocks to Money Markets}

Suppose that the money market rate grows from $\tau_{1}$ to $\tau_{2}$, with $\tau_{2}>\tau_{1}$. From Proposition 1, this affects the bank's optimal lending policy in (5) by depressing the flat-base loan $A_{p, r, \tau}$ and increasing the type-based discrimination $B_{r, \tau, \chi}$. Two effects are in place. First, the hike alters the segmentation of endowments $e$. To see this, let $e_{1}(\tau)$ (respectively, $\left.e_{2}(\tau)\right)$ be the type obtaining a credit line corresponding to $\omega_{e_{1}(\tau)}=\omega^{* *} /(1+\alpha)$ (respectively, $\omega_{e_{2}(\tau)}=\omega^{* *}$ ) from the bank's problem in (5) and define $E_{1} \equiv\left\{0, \ldots, e_{1}\right\}$, $E_{2} \equiv\left\{e_{1}, \ldots, e_{2}\right\}$ and $E_{S} \equiv\left\{e_{2}, \ldots, \bar{e}\right\}$. From Proposition 2, for any generic endowment $e \in E_{1}$ (respectively, $e \in E_{2}$ ) or $e \in E_{S}$, it holds that $\omega_{e} \in D^{*}$ (respectively, $\omega_{e} \in D^{* *}$ ) or $\omega_{e} \in S$. Clearly, a shock on $\tau$ may affect the relative sizes of sets $E_{1}, E_{2}$ and $E_{S}$. Second, from the discussion in Section 2.4, all types $e<\hat{e}_{p, r}$ (respectively, $e>\hat{e}_{p, r}$ ) experience a net credit cut (respectively, expansion). Hence, the reshuffling of types and their lending profile will depend on the intensity of the shock as well as the position of $\hat{e}_{p, r}$ relative to $e_{1}\left(\tau_{1}\right)$ and $e_{2}\left(\tau_{1}\right)$.

Two cases are $\mathrm{critical}^{32}$. (i) $\hat{e}_{p, r} \leq e_{1}\left(\tau_{1}\right)<e_{2}\left(\tau_{1}\right)$. Here, the risk profile of the investment is moderate relative to firms' endowment (see (3)). The bank expands the credit lines to at least one type $e \in E_{1}$ and to any type $e \in E_{2}$ and $e \in E_{S}$. Therefore, $e_{1}\left(\tau_{2}\right) \leq e_{1}\left(\tau_{1}\right)$ and $e_{2}\left(\tau_{2}\right) \leq e_{2}\left(\tau_{1}\right)$. As firms in $E_{1}$ are fully constrained, demand for internal credit by any type $e<\hat{e}_{p, r}$ is invariant to higher bank discrimination. As a result of at least one type $e$ switching from $E_{1}$ to $E_{2}$, the demand for ICM credit shrinks. (ii) $e_{1}\left(\tau_{1}\right)<e_{2}\left(\tau_{1}\right)<\hat{e}_{p, r}$. In this case, $e_{1}\left(\tau_{2}\right) \geq e_{1}\left(\tau_{1}\right)$ and $e_{2}\left(\tau_{2}\right) \geq e_{2}\left(\tau_{1}\right)$. The net effect on the demand for internal credit depends on the magnitude of the debt-to-equity ratio $\alpha$ and the hike $\tau_{2}$ relative to the endowment segmentation as induced by $\tau_{1}$. A shock $\tau_{2}>\tau_{1}$ has two opposite effects: one the one hand, it will expand the size of sets $E_{1}$ and $E_{2}$ relative to $E_{S}$. On the other hand, given the debt-to-equity regulations $\alpha$, a shock depressing bank credit bears two implications related to the fact that internal borrowing depends on bank credit $\omega_{e}$. First, it tightens the cap on the maximum amount of internal debt of fully-constrained types in $E_{1}$. Second, as the bank loan is proportional to the endowment type $e$, higher types switching from $E_{S}$ to $E_{2}$ will ask for less ICM credit relative to smaller types. When debt-to-equity regulations are sufficiently tight, the inflow of high types in the pool of $E_{2}$ borrowers may fail to compensate the smaller demand from fully-constrained firms in $E_{1}$. The net effect of shocks on $\tau$ on the demand for ICM credit is therefore ambiguous. The coexistence of these cases implies that there is no monotonic relationship between $\tau$ and the market average profitability $\phi_{r, \tau, \chi, \alpha, \omega^{* *}}$ in (16) in general. Therefore, as the market profitability drives market formation, the response of ICM structure is not monotonic in general to shocks to $\tau>0$. This is

\footnotetext{
${ }^{32}$ The full taxonomy is analyzed in the proof of Proposition 8.
} 
formalized in the following

Proposition 8. Given two ICM architectures $P\left(s, \omega ; \tau_{1}\right)$ and $P^{\prime}\left(s, \omega ; \tau_{2}\right)$ as defined in Theorem 1 with $\tau_{1} \neq \tau_{2}$, it is not possible in general to order $P\left(s, \omega ; \tau_{1}\right)$ and $P^{\prime}\left(s, \omega ; \tau_{2}\right)$ by means of FOSD.

The result is consistent with the ambivalent evidence on the changes to cross-subsidization following a credit crunch. For example, Lee et al. (2009) show that bank credit and cross-subsidization become marginal in determining PUs' investment levels following a tightening to the debt-to-equity ratio and tighter bank regulations. On the other hand, Khanna and Tice (2001) provide abundant evidence on a positive relationship between ICM cross-subsidization and tightening of the external capital markets.

\subsubsection{Shocks to Bank Rates}

With no loss of generality, suppose $r_{2}>r_{1}$. Relative to the previous channel, as rates are competitive, a shock on $r$ bears the additional implication of worsened profitability of production markets ${ }^{33}$ (see Proposition 2). Two cases can emerge, depending on the bank's relative cost of liquidity $\theta$. First, when the cost is sufficiently small, $\theta<1 / 2$, the bank's behavior depends on the riskiness of the investment (see Section 2.4). If the investment risk is high enough (i.e., $p>\bar{p}_{\theta}$ ), a hike $r_{2}>r_{1}$ implies that the risk neutral bank maximizes expected profits with less outstanding credit. Therefore, the bank cuts credit lines to all endowment types on the support. Since internal borrowing depends on bank credit, less bank credit implies a tighter cap on the maximum amount of internal debt. In this scenario, the joint effect of reduced market profitability and tighter bank credit rarefies the ICM structure. Second, if investment risk is sufficiently moderate or the relative cost of liquidity $\theta$ is high enough, $\theta>1 / 2$, the risk neutral bank can decide to selectively expand (respectively, cut) credit provision to a fraction of high-gain (respectively low-gain) types, $e<e_{p, r, \tau}^{*}$ (respectively, $e_{p, r, \tau}^{*}$ ). In this latter case, for reasons similar to the ones extensively discussed for shocks to the money market channel, it is not possible in general to establish an ordering (in terms of FOSD) between different ICM architectures, or in other words, it is unclear ex-ante what is the effect on cross-subsidization of a shock on lending rate $r$. This is formalized in the following

Proposition 9. Consider two ICM architectures $P\left(s, \omega ; r_{1}\right)$ and $P^{\prime}\left(s, \omega ; r_{2}\right)$ as defined in Theorem 1 with $r_{2}>r_{1}$. Let $\theta$ and $\bar{p}_{\theta}$ be as defined in Proposition 1. Then,

1. For $\theta<1 / 2$ and $p>\bar{p}_{\theta}$, it holds that $P\left(s, \omega ; r_{1}\right) \stackrel{F O}{\succ} P^{\prime}\left(s, \omega ; r_{2}\right)$.

2. For all other cases, it is not possible in general to order $P\left(s, \omega ; r_{1}\right)$ and $P^{\prime}\left(s, \omega ; r_{2}\right)$

\footnotetext{
${ }^{33}$ For example, in discussing the effects on Korean firms of interest rate hikes during the Korean Crisis, Borensztein and Lee (2002) find that real money and credit slowed down during the crisis, yet, it is not clear on how significantly domestic credit conditions tightened, as both credit supply and demand felt simultaneously.
} 


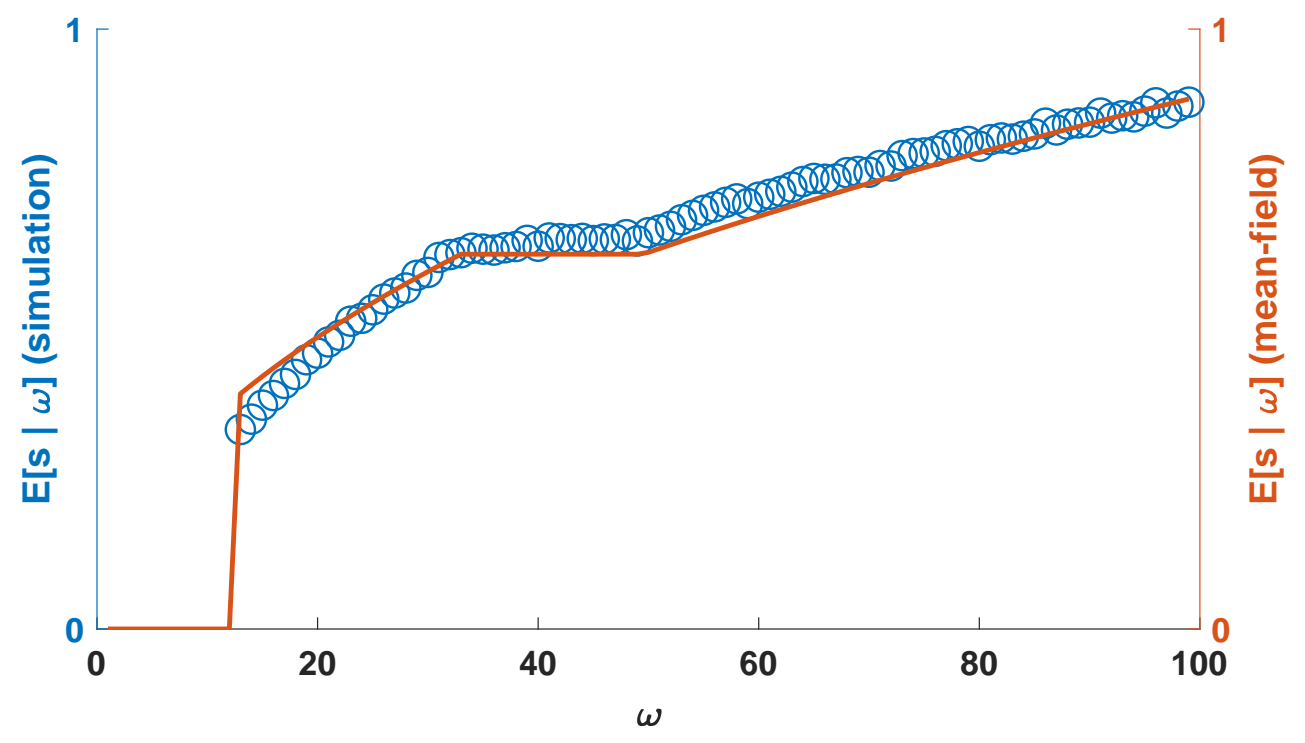

Figure 5: Equilibrium number of outstanding loans per type, $\mathbb{E}[s \mid \omega]$ given the market structure $(p, \alpha, r, \tau, \chi)=(50,0.5,1.01,0.5,0.99)$, endowment structure $e \in\{0, \ldots, 100\}$ and production function $f(\cdot)=\log (\cdot)$. The red line (respectively, the circles) represents the expected number of outstanding loans, $\mathbb{E}[s \mid \omega]$ as derived from the mean-field approximation (20) (respectively, the simulation as per Section 4.1).

by means of FOSD.

Therefore, the effect of bank rate $r$ on the internal lending structure critically depends on the bank's relative cost of liquidity. In particular, when such cost is low enough, a reduction of bank rates triggers an aggressive credit expansion as well as a higher demand for debt motivated by an improvement of good markets. These two effects are jointly responsible for an unambiguous densification of ICM. Proposition 9 matches well with empirical evidence. For example, using a very granular inter-firm lending data set, Shi et al. (2019) find that a localized $16.6 \%$ bank credit expansion within a booming economy can migrate through the ICM and boost PUs' investment by $1 \%$. On the other hand, Proposition 9 also shows that the above case is a knife-edge situation within a more complex taxonomy.

\section{Quantitative Assessment}

\subsection{Set-Up and Diagnostics}

The analytical results presented in Section 3 rest on three technical assumptions. These enable an explicit characterization of the exchange probability $\xi(\cdot)$ (see Section 4) and the study of the ensuing dynamics. In this Section I validate the mean-field analysis by comparing a simulated market formation process against its analytical counterpart as 
derived in Theorem 1. In both simulations and mean-field analysis I assume a common market structure given by $M=(p, \alpha, r, \tau, \chi)=(50,0.5,1.01,0.5,0.99)$, together with an endowment structure $\bar{e}=100$ and production function $f(\cdot)=\log (\cdot)$. The simulated market formation process adheres to the protocol described in Section 2.1 and in Figure 1. I generate an initial ICM made of $N_{0}=\{1,2, . ., 50\}$ PUs with random endowment uniformly distributed across $\{0, \ldots, 100\}$. Then, I let the economy grow for $t=1,2, \ldots, \bar{t}$ periods, with one newcomer accessing the market in every period. I fix the size of the loan to $\ell=1$. For each successful transaction, I update the vector of cash endowments $\left\{K_{t^{\prime}}(t)\right\}_{t^{\prime}=1}^{t}, \forall t^{\prime}<t$. At the end of period $t=\bar{t}$, I construct the vector of type endowments $\left\{K_{\omega}(\bar{t})\right\}_{\omega \in \Omega}$ in which each element $K_{\omega^{\prime}}(\bar{t})$ is defined as $K_{\omega^{\prime}}(\bar{t}) \equiv(1 / \bar{t}) \sum_{i=1}^{\bar{t}} 1_{\omega_{i}=\omega^{\prime}} K_{i}(\bar{t})$, where $1_{(\cdot)}$ is the indicator function taking value 1 when the condition in parentheses is matched and zero otherwise. Therefore, $K_{\omega^{\prime}}(\bar{t})$ contains the average number of outstanding loans per type of lender $\omega \in \Omega$ at the end of the simulation. I fix $\bar{t}=500$. Lastly, I average $\left\{K_{\omega}(\bar{t})\right\}_{\omega \in \Omega}$ across $M=500$ simulations. In Figure 5 I report the standardized average number of loans $s$ per type $\omega$, both for Simulations and mean-field analysis (Theorem 1). As it stands from the graph, the mean-field analysis provides a very good qualitative approximation of the lending structure as observed in the simulated market.

\subsection{Comparative Statics: The Effect of Shocks on Equilibrium ICM}

In the following, I use the mean-field derivation of the ICM architecture (Theorem 1) to explore the quantitative implications of shocks to the channels analyzed in Sections 3.3-3.5. Unless otherwise stated, the set-up corresponds to the one adopted in Section 4.1.

\subsubsection{Shocks to Debt-to-Equity Regulations}

In this section I explore the effects of shocks to the debt-to-equity regulation on the equilibrium ICM architecture. Everything else fixed, four debt-to-equity configurations are considered, $\alpha \in\{0.25,0.5,0.75,1\}$. The results are collected in Figure 6. In the figure, in each row, the central (respectively, right) column depicts the equilibrium bank lending policy $\omega_{e}$ (respectively, the equilibrium cash holdings $K_{\omega}$ ) for any type $e \in\{0, \ldots, \bar{e}\}$ (respectively, $\omega \in \Omega$ ). The left column contains the heat-maps of the densities of the equilibrium ICM architectures $p(s, \omega ; \alpha)$ as defined in (20), in which a darker (respectively, lighter) color captures smaller (respectively, higher) density. The loosening of $\alpha$ from $\alpha=0.25$ to $\alpha=1$ ( corresponding to reading Figure 6 from top to bottom) leads to three main observations. First, the bank's equilibrium lending policy (central column) is not impacted by a shock on $\alpha$. Second, while the size of the set of non-borrowers $S$ is fixed across shocks, the size of fully (respectively, partially) constrained firms shrinks (respectively, expands), coherently with Proposition 5. Third, by observing the compar- 
ative statics of the equilibrium ICM architecture across shocks, we confirm that better debt-to-equity regulations lead to an unambiguous densification of cross-subsidization for all types $\omega \in \Omega$.

\subsubsection{Shocks to Market Price}

I modify the exercise of 4.2 .1 by considering four alternative price configurations, $p \in$ $\{50,50.5,51,51.5\}$, everything else fixed. The exercise is reported in Figure 7. Similar to a shock on debt-to-equity rate $\alpha$, an improvement in the profitability of the good market, reflected in price $p$ increasing from $p=50$ to $p=51.5$ (corresponding to reading Figure 7 from top to bottom) does not affect the bank's lending policy (so that the curves in the central column of Figure 7 are fixed) and unambiguously densifies the ICM architecture across all types $\omega \in \Omega$, as predicted by Proposition 7 . However, differently from a shock to debt-to-equity regulations, a change in price reduces the size of the set of non-constrained types $\omega \in S$ relative to the set of fully and partially constrained agents, respectively given by $\omega \in D^{*}$ and $\omega \in D^{* *}$. This translates in a shorter length of the top segment in the distribution of cash holdings $K_{\omega}$, corresponding to $K_{\omega}, \omega \in S$. 


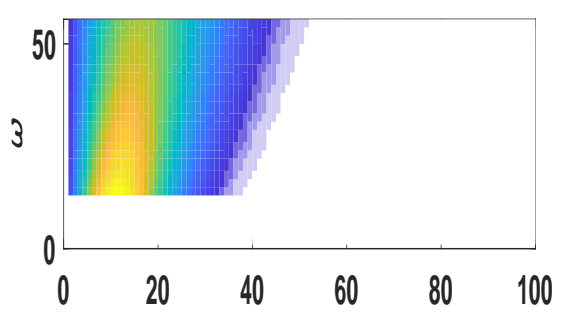

\section{Effect of Increment on Debt-10-Equity $\alpha$}
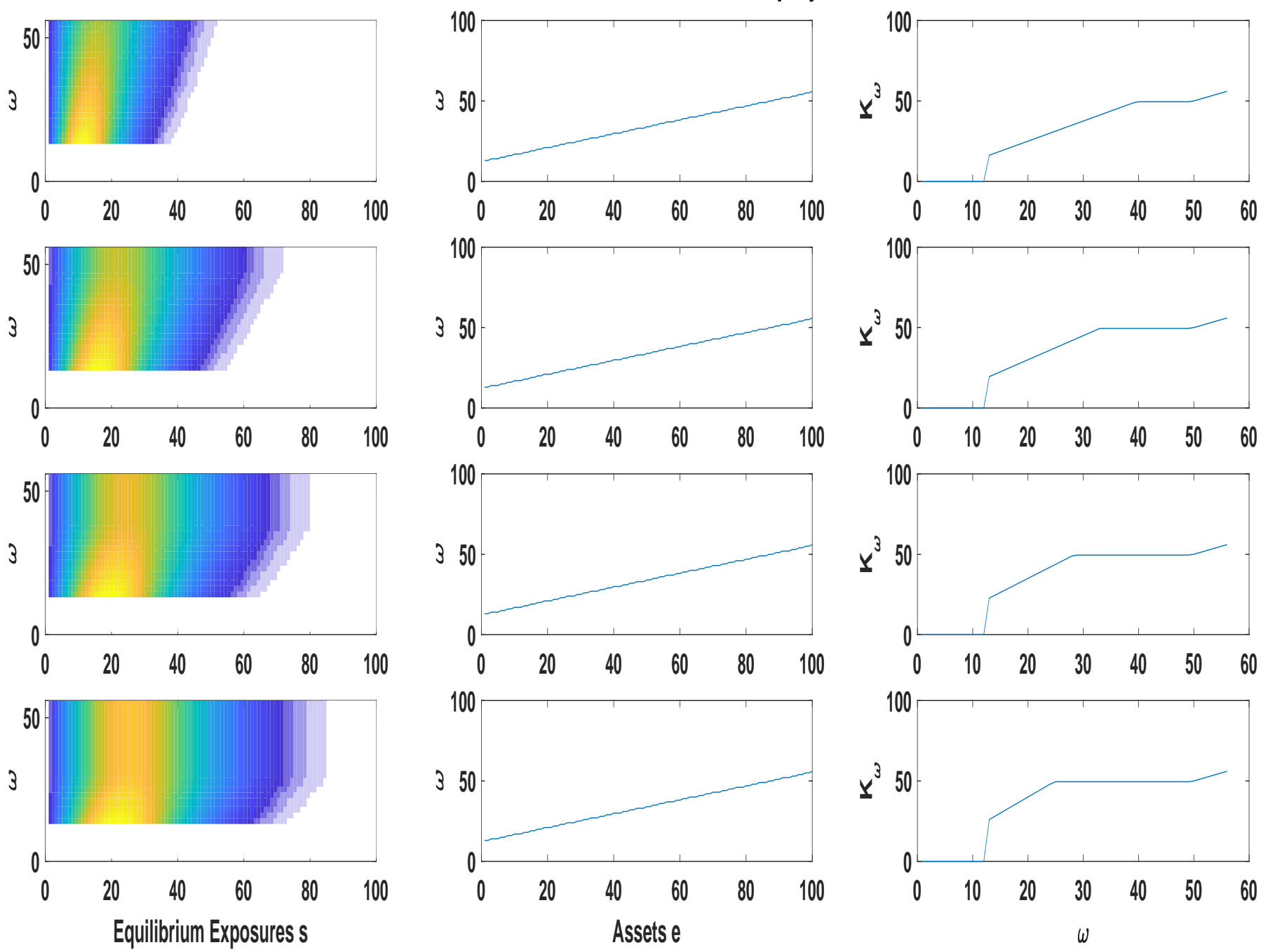

Figure 6: From top to bottom: the effect of increasing the internal debt-to-equity ratio $\alpha$ for $\alpha \in\{0.25,0.5,0.75,1\}$, given market structure $(p, r, \tau, \chi)=(50,1.01,0.5,0.99)$ and $\bar{e}=100$ and $f(\cdot)=\log (\cdot)$. (Left.) Heat-maps of the equilibrium class $p(s, \omega ; \alpha)$ as defined in (20), in which darker (respectively, lighter) colors capture smaller (respectively, higher) density (Center.) The equilibrium lending policy $\omega_{e}$. (Right.) The equilibrium cash holdings $K_{\omega}$ as a function of $e \in\{0, \ldots, \bar{e}\}$. The loosening of $\alpha$ from $\alpha=0.25$ to $\alpha=1$ has three effects. First, the bank's equilibrium lending policy (central column) is not impacted by a shock on $\alpha$. Second, while the size of the set of non-borrowers $S$ is fixed across shocks, the size of fully (respectively, partially) constrained firms shrinks (respectively, expands), coherently with Proposition 5. Third, by observing the comparative statics of the equilibrium ICM architecture across shocks (left column), we confirm that better debt-to-equity regulations lead to an unambiguous densification of cross-subsidization for all types $\omega \in \Omega$. 


\section{Effect of Increment on Market Pricep}
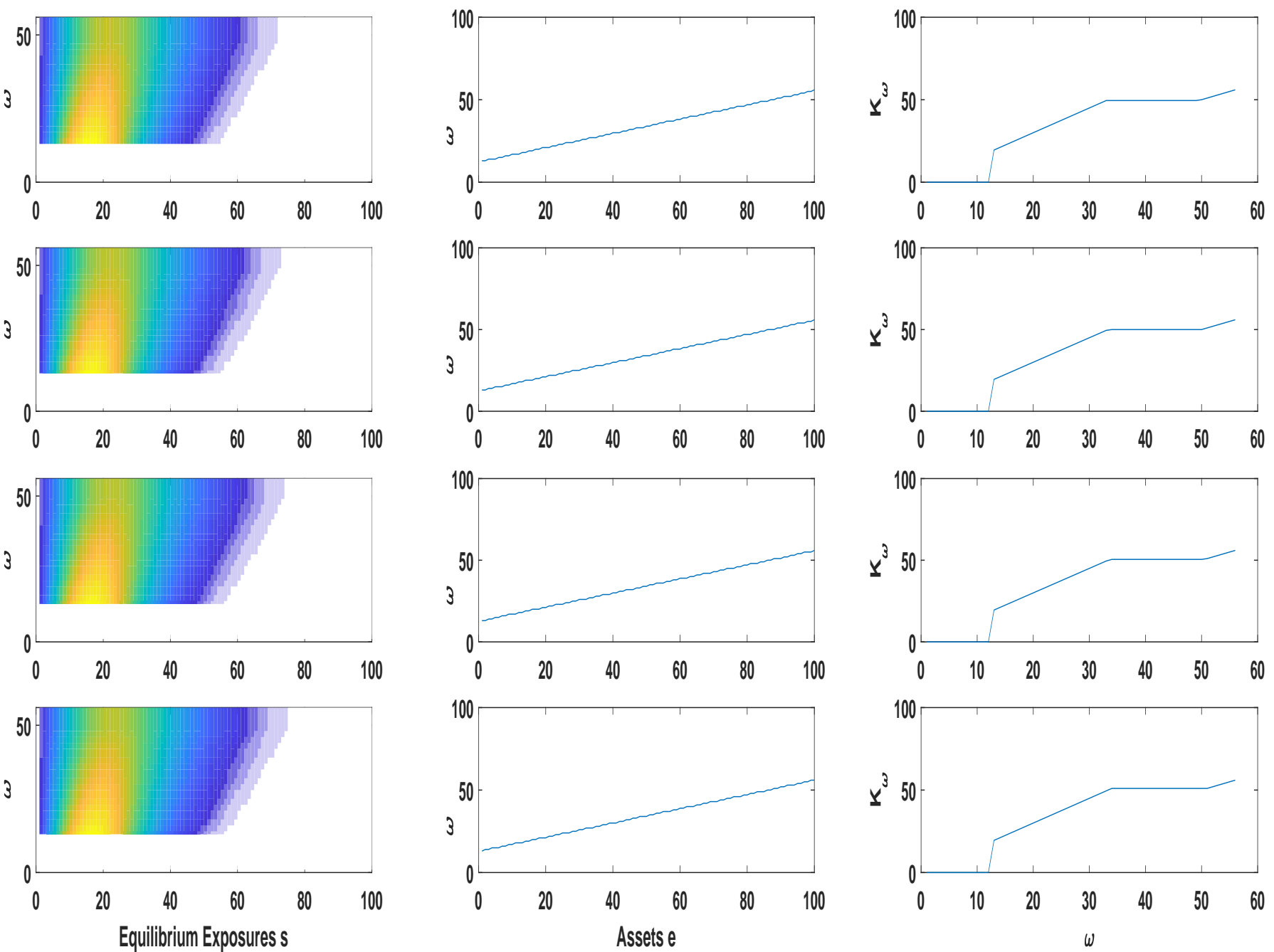

Figure 7: From top to bottom: the effect of increasing the price in the final good market $p$ with $p \in\{50,50.5,51,51.2\}$, given market structure $(\alpha, r, \tau, \chi)=(0.5,1.01,0.5,0.99)$ and $\bar{e}=100$ and $f(\cdot)=\log (\cdot)$. (Left.) Heat-map of the equilibrium class $p(s, \omega ; p)$ as defined in (20), in which darker (respectively, lighter) colors capture smaller (respectively, higher) density (Center.) The equilibrium lending policy $\omega_{e}$. (Right.) The equilibrium cash holdings $K_{\omega}$ as a function of $e \in\{0, \ldots, \bar{e}\}$. Better market profitability, as reflected by price $p$ increasing from $p=50$ to $p=51.5$ does not affect the bank's lending policy (so that the curves in the central column are fixed) and unambiguously densifies the ICM architecture across all types $\omega \in \Omega$. However, differently from a shock to debt-to-equity regulations, a change in price reduces the size of the set of non-constrained types $\omega \in S$ relative to the set of fully and partially constrained agents, respectively given by $\omega \in D^{*}$ and $\omega \in D^{* *}$. This translates in a shorter length of the top segment in the distribution of cash holdings $K_{\omega}$, corresponding to $K_{\omega}, \omega \in S$. 


\section{Effect of Increment of money-market cost $\tau$}
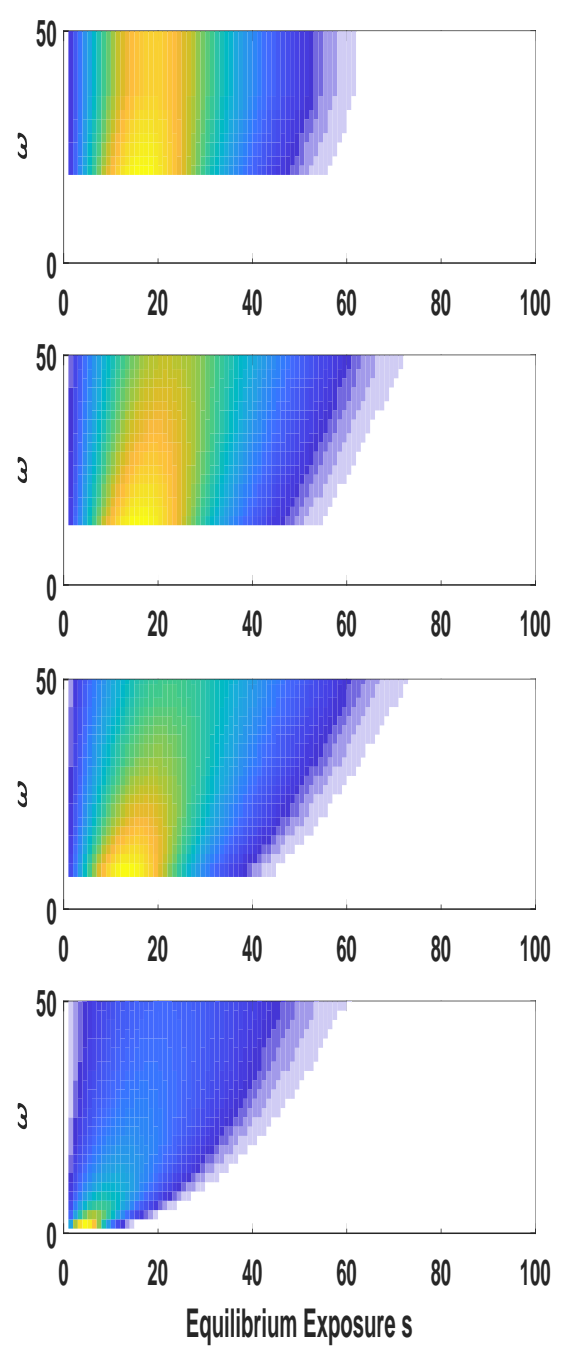
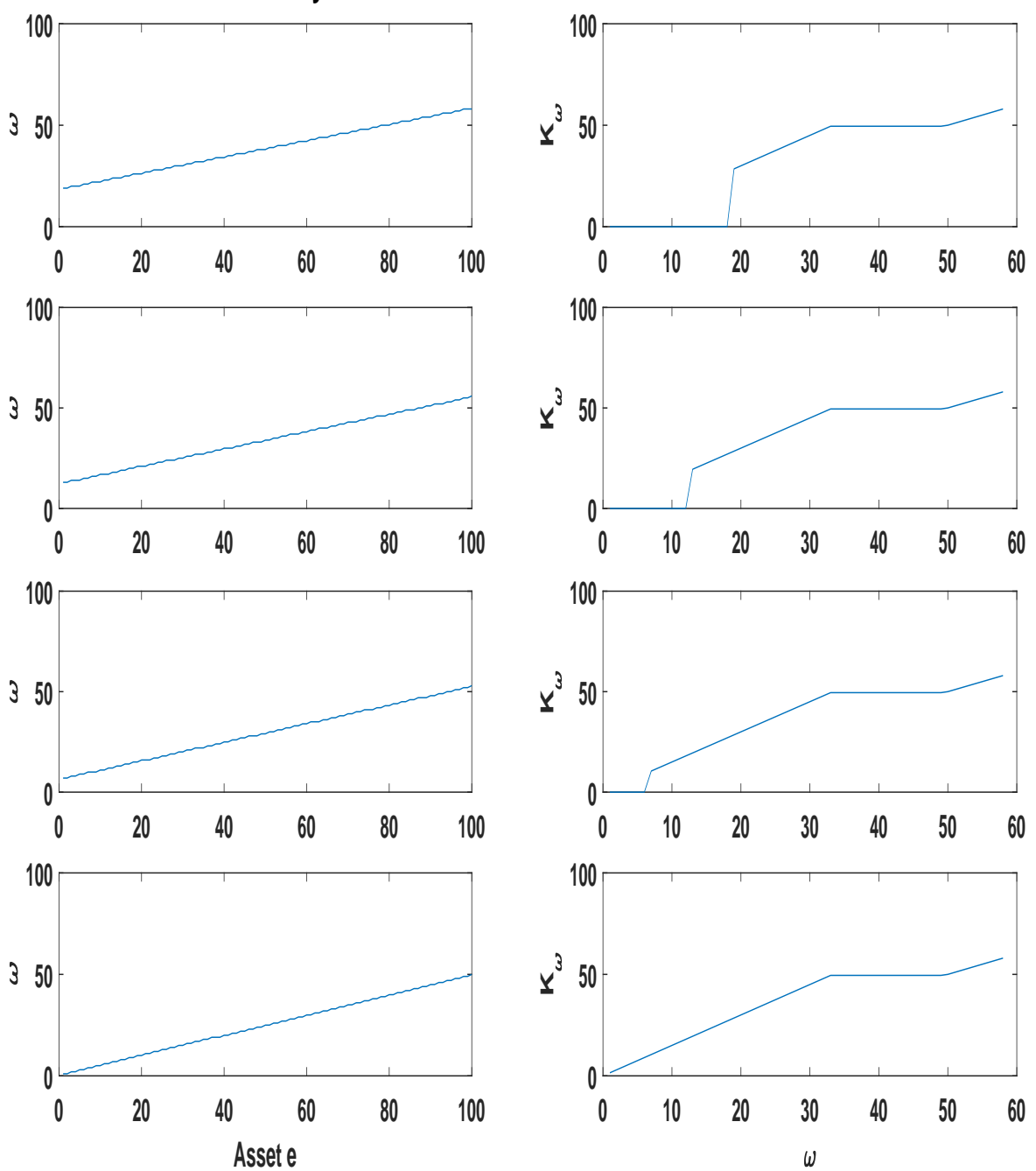

Figure 8: From top to bottom: the effect of increasing the cost of money market $\tau$ with $\tau \in\{0.25,0.5,0.75,1\}$, given market structure $(p, \alpha, r, \chi)=(50,0.5,1.01,0.99)$ and $\bar{e}=100$ and $f(\cdot)=\log (\cdot)$. (Left.) Heat-map of the equilibrium class $p(s, \omega ; p)$ as defined in $(20)$, in which darker (respectively, lighter) colors capture smaller (respectively, higher) density (Center.) The equilibrium lending policy $\omega_{e}$. (Right.) The equilibrium cash holdings $K_{\omega}$ as a function of $e \in\{0, \ldots, \bar{e}\}$. With this parametrization, $e_{1}<e_{2}<\bar{e}<\hat{e}_{p, r}$ (see Case (ii) as described in Section 3.5). As money market cost increases, the bank's lending policy $\omega_{e}$ (central column) tightens for any type $e \in\{0, \ldots, \bar{e}\}$, with lower types being proportionally more affected than higher types. Consequently, the distribution of cash holdings $K_{\omega}$ adjusts to the credit-crunch with a leftward shift, as a tighter lending policy translates into the creation of new lending profiles $\omega_{e}$. Lastly, by comparing the densities of the ICM architectures (left column), it is clear that there is no monotonic relationship between the intensity of internal lending and and credit tightening, thus validating the co-existence of the two tensions discussed in the main body of Section 3.5. 

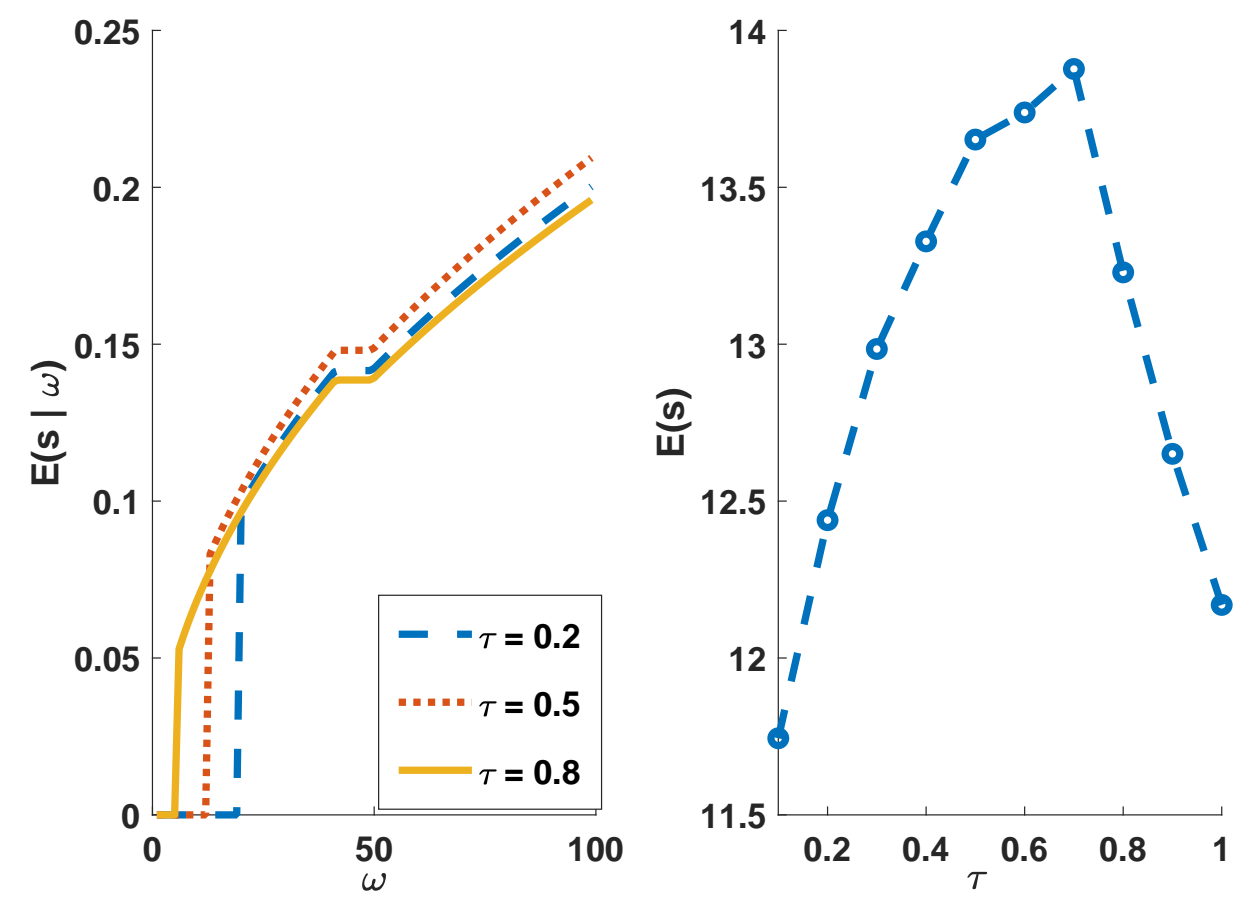

Figure 9: The effect of increasing the cost of money market $\tau$, with $\tau \in\{0.1, \ldots, 1.0\}$, given market structure $(p, \alpha, r, \chi)=(50,0.3,1.01,0.99)$ and $\bar{e}=200$ and $f(\cdot)=\log (\cdot)$. (Left.) Average number of internal loans per type $\omega, \mathbb{E}[s \mid \omega]$, for three cost configurations $\tau \in\{0.2,0.5,0.8\}$, respectively given by the dashed blue, dotted red and solid yellow lines. These lines are not monotonic in $\tau$, hence $P(\omega, s ; \tau)$ violate FOSD. (Right.) Total number of ICM loans $\mathbb{E}[s]$ for $\tau \in\{0.1, \ldots, 1\}$. Again, the violation of FOSD is sufficiently strong to generate a non-monotonic relationship between cost $\tau$ and the total number of outstanding loans.

\subsubsection{Shocks to Money-Market Cost}

In this section I perform two exercises. First, I conduct a mean-field analysis of the effect of shocks on money market cost $\tau$ on the model's equilibrium quantities. The following four cost configurations are considered, $\tau \in\{0.25,0.5,0.75,1\}$, everything else fixed as per the set-up of Section 4.1. The results are reported in Figure 8. Notice that for the selected parametrization, it is easy to show that $e_{1}<e_{2}<\bar{e}<\hat{e}_{p, r}$. Hence, the example falls within case $(i i)$ described in Section 3.5.1. I make the following observations. First, as money market cost increases (corresponding to reading the Figure from top to bottom) the bank's lending policy $\omega_{e}$ (central column of Figure 8) tightens for any type $e \in\{0, \ldots, \bar{e}\}$, with lower types being proportionally more affected than higher types ${ }^{34}$. Second, the distribution of cash holdings $K_{\omega}$ adjusts to the credit-crunch with a leftward shift, as a tighter lending policy translates into the creation of new lending profiles $\omega_{e}$. In other words, given $\tau$ and $\tau^{\prime}$, with $\tau^{\prime}>\tau$ and $e=0, \omega_{0}\left(\tau^{\prime}\right)<\omega_{0}(\tau)$. Second, by comparing the densities of the ICM architectures (left column), it is clear that there

\footnotetext{
${ }^{34}$ More precisely, the bank lending policy $\omega_{e}$ pivots around the pivotal type $\hat{e}_{p, r}$.
} 
is no monotonic relationship between the intensity of internal lending and and credit tightening, thus validating the co-existence of the two tensions discussed in the previous paragraph.

Lastly, to inspect more in detail the lack of monotonic relationship discussed above and in Proposition 8, I plot the average number of loans for various configurations of $\operatorname{cost} \tau$. This is done in Figure 9. On the Left pane, I plot the average number of internal loans per type $\omega, \mathbb{E}[s \mid \omega]$, for three cost configurations $\tau \in\{0.2,0.5,0.8\}$, respectively given by the dashed blue, dotted red and solid yellow lines. A necessary condition for FOSD to hold is that these lines are monotonic in $\tau$. However, this is indeed not the case, as the curve referred to $\tau=0.2$ sits in between the other two curves. On the Right pane I plot the total number of ICM loans $\mathbb{E}[s]$ for $\tau \in\{0.1, \ldots, 1.0\}$. Here, the violation of FOSD, as originated by the two tensions described above, is sufficiently strong to generate a non-monotonic relationship between cost $\tau$ and the total number of outstanding loans in the ICM. 


\section{Effect of Increment of Bank Lending Rater}
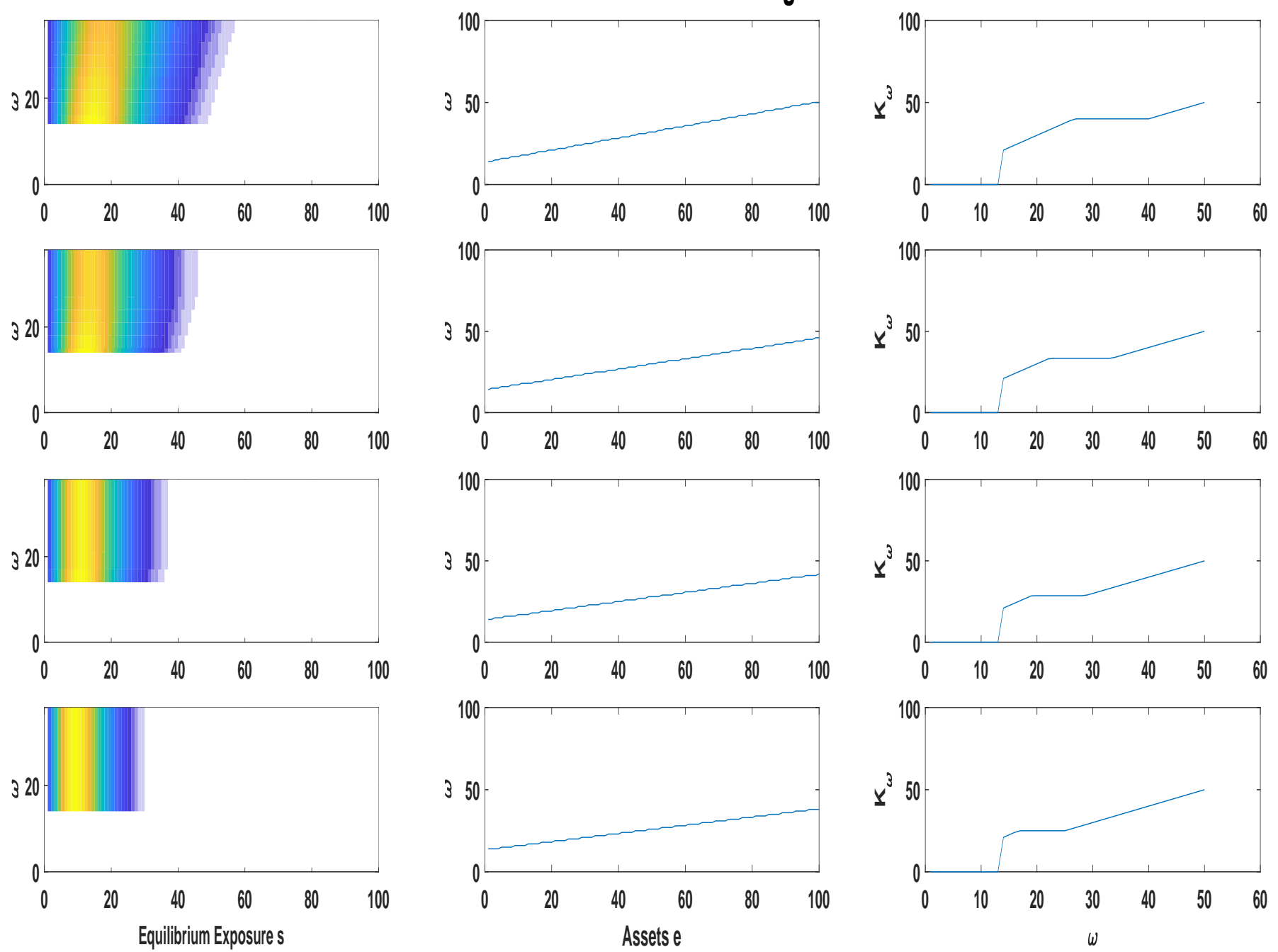

Figure 10: From top to bottom: the effect of increasing the bank rate $r$ with $r \in$ $\{2.1,2.2,2.3,2.4\}$, given market structure $(p, \alpha, \tau, \chi)=(50,0.5,0.5,0.99)$ and $\bar{e}=100$ and $f(\cdot)=\log (\cdot)$. (Left.) Heat-map of the equilibrium class $p(s, \omega ; r)$ as defined in (20), in which darker (respectively, lighter) colors capture smaller (respectively, higher) density (Center.) The equilibrium lending policy $\omega_{e}$. (Right.) The equilibrium cash holdings $K_{\omega}$ as a function of $e \in\{0, \ldots, \bar{e}\}$. With this parametrization, $\theta<0.5$ (see Proposition 9). As rates increase, the bank's lending policy $\omega_{e}$ (central column) tightens for any type $e \in\{0, \ldots, \bar{e}\}$. Hence, the distribution of cash holdings $K_{\omega}$ (Right column) adjusts to the credit-crunch with a small leftward shift (similarly to a hike in $\tau$, see Figure 8). However, as an increment in $r$ is also reflective of a loss of profitability in the production market, the set of pure lenders $S$ expands relative to the other two sets. The result of these two counter-balancing forces shows a prevalence of the real driver, as ICM architectures (depicted in Left column) progressively rarefy. Therefore, it holds the FOSD ordering identified in Proposition 9 for $\theta<0.5$. 

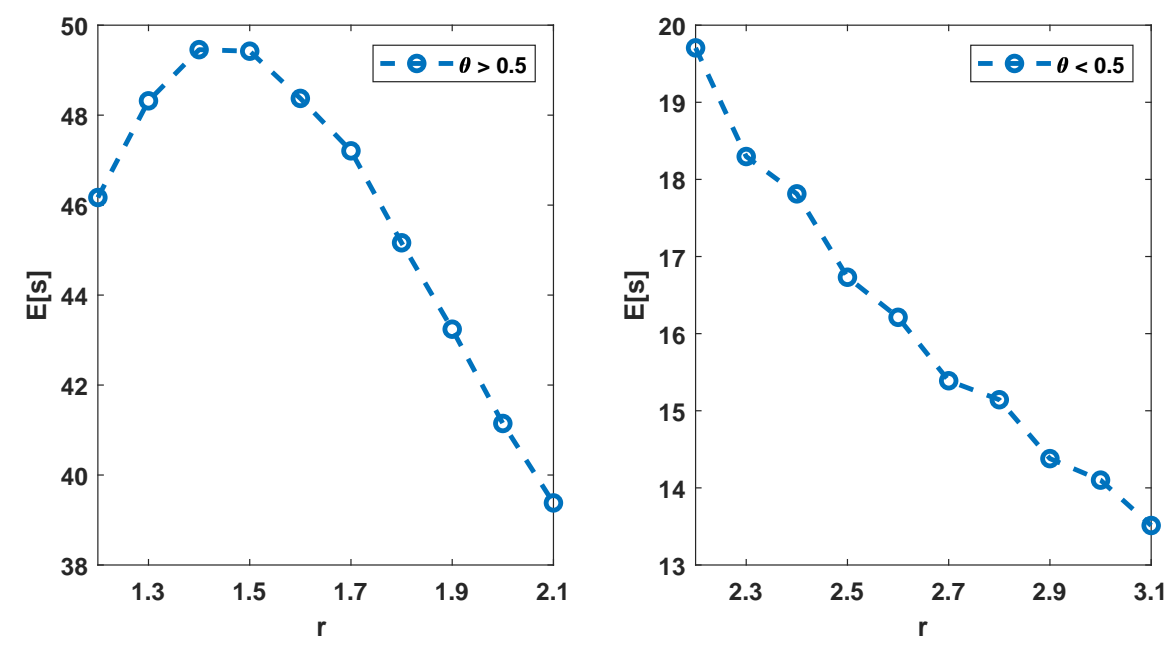

Figure 11: The effect of increasing bank rates $r$ on the total expected number of loans $\mathbb{E}[s]$, for two alternative configurations such that $\theta>0.5$ (Left Pane) or $\theta<0.5$ (Right Pane), given market structure $(p, \alpha, \theta, \chi)=(100,0.3,0.5,0.99)$ and $\bar{e}=200$ and $f(\cdot)=\log (\cdot)$. Clearly, FOSD does not apply with certainty only in the configurations such that $\theta>0.5$ (Left pane).

\subsubsection{Shock to Bank Lending Rate}

Lastly, I study the mean-field effect on the model's equilibrium quantities of shocks to interest rates. I perform two exercises. First, I compute the model's equilibrium quantities for four configurations $r \in\{2.1,2.2,2.3,2.4\}$ given the set-up described in Section 4.1. The results are reported in Figure 10. Notice that for this parametrization, it holds that $\theta<0.5$, therefore we predict FOSD applies between ICM structures (see Proposition 9). I make three observations. First, as rates increase (corresponding to reading the Figure from top to bottom) the bank's lending policy $\omega_{e}$ (central column of Figure 10) tightens for any type $e \in\{0, \ldots, \bar{e}\}$. Second, the distribution of cash holdings $K_{\omega}$ adjusts to the credit-crunch with a small leftward shift (similarly to a hike in $\tau$ ). However, as an increment in $r$ is also reflective of a loss of profitability in the production market, the set of pure lenders $S$ expands relative to the other two sets. Third, by comparing the densities of the ICM architectures (left column), the FOSD ordering identified in Proposition 9 for $\theta<0.5$ is evident: as rates grow, all types reduce lending.

Second, I validate the role of $\theta$ in light of Proposition 9 by plotting the total expected number of loans $\mathbb{E}[s]$ for various configurations of rate $r$ and $p>\bar{p}_{\theta}$. This is done in Figure 11, where, on the Left pane (respectively, Right pane), I test an array of rates $r$ such that $\theta<0.5$ (respectively, $\theta>0.5$ ). As it stands clear from the graph, FOSD does not apply with certainty only in the configurations such that $\theta<0.5$. 

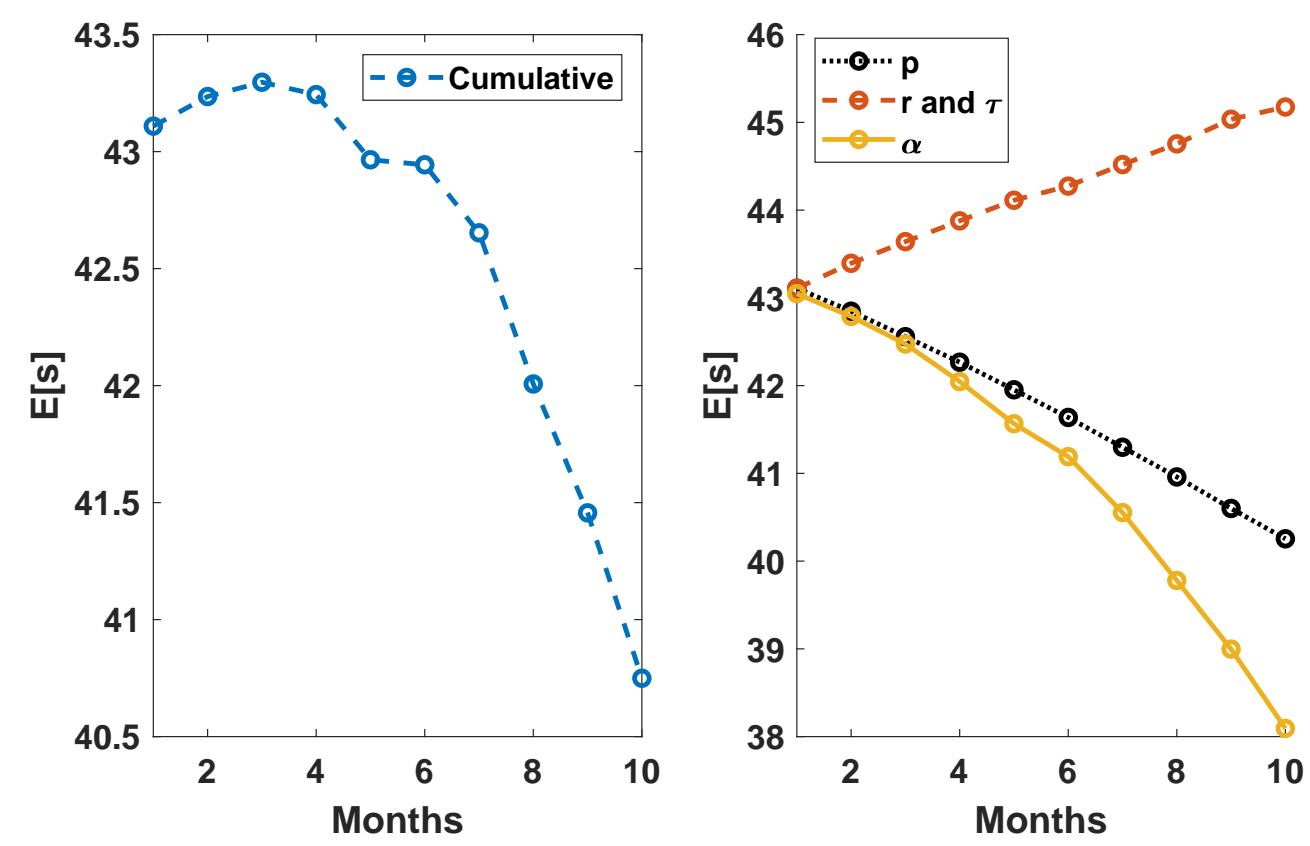

Figure 12: The effect on total expected outstanding loans $\mathbb{E}[s]$ of the shock structure described in Section 4.3. The initial market structure corresponds to $M_{1}=(50,4,0.175,0.125,0.9)$. (Left Pane) The shock structure is linearly shifted from $M_{1}$ to $M_{10}=(46.5,2,0.375,0.35,0.8)$. The compounded effect of the shocks is negative for a sufficiently high magnitude. (Right Pane) Three major shocks are considered and individually increased keeping all other shocks fixed: the change of market profitability $p$, the joint effect of a change in money market funds $\tau$ and overnight lending $r$ and the debt-to-equity regulations $\alpha$. When shocks are individually applied on the ICM in isolation, the tightening of the financial market affects the ICM structure differently from the debt-to-equity and market profitability channels. The tightening of the financial market, taken in isolation from other shocks, increases the density of the ICM structure, reflecting the functioning of the credit-reallocation channel. At the same time, the magnitude of such effect is not sufficiently strong to overcome the reduction in density as caused by the two alternative channels.

\subsection{Matching the Stylized Facts of the Korean Crisis}

To conclude, I develop a simple exercise to show a possible route of application of the analytical framework developed in this paper. I consider some of the main qualitative features of the so called "Korean crisis". This has been a rapid economic downturn hitting the Korean economy in 1997-1998 as a consequence of the 1997 Asian Financial crisis $^{35}$. I explore the effect on the ICM structure $P(s, \omega)$ derived in Theorem 1 of a set of intertwined shocks. I argue that the model can be instrumental in disentangling the contribution of each channel to the aggregate shock, which I measure in terms of variations to the density of the ICM.

Calibration. I focus the analysis on the following empirical facts (see Borensztein and

\footnotetext{
${ }^{35}$ For a comprehensive description of the crisis, I direct the reader to Almeida et al. (2015) and the literature therein cited.
} 
Lee, 2002, Lee et al., 2009, Almeida et al., 2015 and Lim (2012)). First, the year-on-year rate of growth of real sales for the average firm dropped from $4.3 \%$ in 1997 to $-6.8 \%$ in the first half of 1998. Second, the overnight call rate soared from $12.5 \%$ to $32 \%$ at the peak of the crisis. On the other hand, for a comparable period, overdraft lending rate increased from $17.1 \%$ to $37.5 \%$. Third, following the crisis, BGs firms were required to drastically reduce their debt-to-equity ratios from an average of $400 \%$ to a maximum of $200 \%$. Forth, at the peak of the crisis, the percentage of defaulted commercial bills jumped from about $10 \%$ to $20 \%$. To obtain sufficient heterogeneity at PUs level, I will hold that firms are uniformly distributed on the interval $e \in\{0, \ldots, 100\}$. This simple structure ${ }^{36}$ retains enough heterogeneity at endowment level, yet it is simple enough to enable a focus on the remaining channels of heterogeneity. I discretionary set profitability of the production market $p$ before the crisis to $50 \%$ of the highest endowment ${ }^{37} \bar{e}$. Lastly, with no loss of generality, I set the loan size to $\ell=1$. Let $M_{T} \equiv(p, \alpha, r, \tau, \chi)$ be the market structure of the economy in month $T$, with $T=1$ and $T=10$ respectively coinciding with the beginning and the end of the crisis. Using the empirical facts above, I impose as starting vector $M_{1}=(50,4,0.175,0.125,0.9)$ and as end vector $M_{10}=(46.5,2,0.375,0.35,0.8)$. Each element of the vector $M_{T}, T=2, \ldots, 9$ is obtained by imposing a linear uniform shock variation to the corresponding element in vector $M_{T-1}$. For each month $T$, I use the market structure $M_{T}$ to compute the associated analytical ICM architecture $P_{T}(s, \omega)$ as derived in (19) (Theorem 1), and use the latter to obtain the total expected outstanding loans in month $T, \mathbb{E}_{T}[s]$, that is our proxy for studying the density of ICM.

Results. The empirical literature identified two important regularities in the aftermath of the crisis. First, the overall level of cross-subsidization in ICMs has substantially rarefied (Lee et al., 2009). Secondly, a credit crunch limited the availability of credit to firms (Lim, 2012), however, it is not clear on how significantly domestic credit conditions tightened: as both credit supply and demand felt simultaneously in the crisis period, it is not clear whether credit supply was really a binding constraint (Borensztein and Lee, 2002). In Figure 12, I report the results of two exercises. On the Left Pane, I show the cumulative effect on total monthly expected outstanding loans, $\mathbb{E}_{T}[s]$, of all shocks discussed above. On the Right pane, I report the individual contribution of three major shock channels. In this exercise, I individually vary each channel by taking all other shock sources fixed. These channels are: the change of market profitability $p$, the joint effect of a change in money market funds $\tau$ and overnight lending $r$ and the debt-toequity regulations $\alpha$. In terms of aggregate effects, it is clear that the compounded effect

\footnotetext{
${ }^{36}$ It is indeed possible to construct a more refined endowment distribution using, for example, the Korea Listed Companies Association Data-set (see, for instance, Lim, 2012).

${ }^{37}$ In untabled simulations I try alternative starting values with no effect on the qualitative results presented here.
} 
of the shocks is negative, and as such the structure rarefies as shocks jointly intensify. However, when shocks are individually applied on the ICM in isolation, it is interesting to notice that the tightening of the financial market affects the ICM structure differently from the debt-to-equity and market profitability channels. In particular, I find that the tightening of the financial market, taken in isolation from other shocks, would contribute to an increased densification of the ICM structure, reflecting the functioning of the creditreallocation channel described by Almeida and Wolfenzon (2006) and Khanna and Tice (2001). At the same time, the magnitude of such effect is not sufficiently strong to overcome the reduction in densification as caused by the two alternative channels, that is profitability of markets and debt-to-equity ratio. This latter result is coherent with the literature that attributed Korean credit crunch to the joint effect of banks' "flight to credit quality" (Borensztein and Lee, 2002) and tightening of internal debt-to-equity regulations (Lee et al., 2009, Lim (2012)).

\section{Conclusion}

In this paper I presented a model in which an internal capital market emerges from three leading drivers: production incentives, debt-to-equity ratio and bank credit rationing. The formation mechanism delivers neat predictions with respect to the long-term implications on the structure of the intensity of cross-subsidization between firms and provide guidance on how to study the effect of complex shocks on internal capital markets. 


\section{REFERENCES}

Allen, Franklin, Yiming Qian, Guoqian Tu, and Frank Yu, "Entrusted loans: A close look at China's shadow banking system," Journal of Financial Economics, 2019, 133 (1), 18-41.

Almeida, Heitor, Chang-Soo Kim, and Hwanki Brian Kim, "Internal capital markets in business groups: Evidence from the Asian financial crisis," The Journal of Finance, 2015, 70 (6), 2539-2586.

_, Sang Yong Park, Marti G Subrahmanyam, and Daniel Wolfenzon, "The structure and formation of business groups: Evidence from Korean chaebols," Journal of Financial Economics, 2011, 99 (2), 447-475.

Almeida, Heitor V and Daniel Wolfenzon, "A theory of pyramidal ownership and family business groups," The journal of finance, 2006, 61 (6), 2637-2680.

Boot, Arnoud WA, Stuart I Greenbaum, and Anjan V Thakor, "Reputation and discretion in financial contracting," The American economic review, 1993, pp. 11651183.

Borensztein, Eduardo and Jong-Wha Lee, "Financial crisis and credit crunch in Korea: evidence from firm-level data," Journal of Monetary Economics, 2002, 49 (4), $853-875$.

Bramoullé, Yann, Sergio Currarini, Matthew O Jackson, Paolo Pin, and Brian W Rogers, "Homophily and long-run integration in social networks," Journal of Economic Theory, 2012, 147 (5), 1754-1786.

Buchuk, David, Borja Larrain, Francisco Muñoz, and Francisco Urzúa, "The internal capital markets of business groups: Evidence from intra-group loans," Journal of Financial Economics, 2014, 112 (2), 190-212.

Cestone, Giacinta and Chiara Fumagalli, "The strategic impact of resource flexibility in business groups," RAND Journal of Economics, 2005, pp. 193-214.

Eales, Robert and Edmund Bosworth, "Severity of loss in the event of default in small business and larger consumer loans," Journal of Lending and Credit Risk Management, 1998, 80, 58-65.

Freimer, Marshall and Myron J Gordon, "Why bankers ration credit," The Quarterly Journal of Economics, 1965, 79 (3), 397-416. 
Gertner, Robert H, David S Scharfstein, and Jeremy C Stein, "Internal versus external capital markets," The Quarterly Journal of Economics, 1994, 109 (4), 12111230.

Gilchrist, Simon and Egon Zakrajšek, "The importance of credit for macroeconomic activity: identification through heterogeneity," in "Market behaviour and macroeconomic modelling," Springer, 1998, pp. 129-157.

Gopalan, Radhakrishnan, Vikram Nanda, and Amit Seru, "Affiliated firms and financial support: Evidence from Indian business groups," Journal of Financial Economics, 2007, 86 (3), 759-795.

Grimmett, Geoffrey and David Stirzaker, Probability and random processes, Oxford university press, 2019.

Holod, Dmytro and Joe Peek, "Capital constraints, asymmetric information, and internal capital markets in banking: New evidence," Journal of Money, Credit and Banking, 2010, 42 (5), 879-906.

Hoshi, Takeo, Anil Kashyap, and David Scharfstein, "Corporate structure, liquidity, and investment: Evidence from Japanese industrial groups," the Quarterly Journal of economics, 1991, 106 (1), 33-60.

Huang, Chuan C, Dennis Kira, and Ilan Vertinsky, "Stochastic dominance rules for multi-attribute utility functions," The Review of Economic Studies, 1978, 45 (3), $611-615$.

Jackson, Matthew $\mathrm{O}$ and Brian W Rogers, "Meeting strangers and friends of friends: How random are social networks?," American Economic Review, 2007, 97 (3), 890-915.

Khanna, Naveen and Sheri Tice, "The bright side of internal capital markets," The Journal of Finance, 2001, 56 (4), 1489-1528.

Khanna, Tarun and Krishna Palepu, "Is group affiliation profitable in emerging markets? An analysis of diversified Indian business groups," The journal of finance, 2000, 55 (2), 867-891.

_ and Yishay Yafeh, "Business groups in emerging markets: Paragons or parasites?," Journal of Economic literature, 2007, 45 (2), 331-372.

Lee, Sangwoo, Kwangwoo Park, and Hyun-Han Shin, "Disappearing internal capital markets: Evidence from diversified business groups in Korea," Journal of Banking E Finance, 2009, 33 (2), 326-334. 
Leland, Hayne E, "Financial synergies and the optimal scope of the firm: Implications for mergers, spinoffs, and structured finance," The Journal of finance, 2007, 62 (2), 765-807.

Leuz, Christian and Felix Oberholzer-Gee, "Political relationships, global financing, and corporate transparency: Evidence from Indonesia," Journal of financial economics, 2006, 81 (2), 411-439.

Levy, Haim and Jacob Paroush, "Multi-period stochastic dominance," Management Science, 1974, 21 (4), 428-435.

Lim, Kyung-Mook, "Structural Fundamentals of Korean Corporations: This Time Was Different," in "Global Economic Crisis," Edward Elgar Publishing, 2012.

Luciano, Elisa and Giovanna Nicodano, "Guarantees, leverage, and taxes," The Review of Financial Studies, 2014, 27 (9), 2736-2772.

Nicodano, Giovanna and Luca Regis, "A trade-off theory of ownership and capital structure," Journal of Financial Economics, 2019, 131 (3), 715-735.

Porta, Rafael La, Florencio Lopez de Silanes, Andrei Shleifer, and Robert Vishny, "Investor protection and corporate valuation," The journal of finance, 2002, 57 (3), 1147-1170.

Riley, John G, Essential microeconomics, Cambridge University Press, 2012.

Samphantharak, Krislert, "Internal capital markets in business groups," Available at SSRN 975562, 2006.

Shi, Ms Yu, Robert M Townsend, and Wu Zhu, Internal capital markets in business groups and the propagation of credit supply shocks, International Monetary Fund, 2019.

Shin, Hyun-Han and Young S Park, "Financing constraints and internal capital markets: Evidence from Koreanchaebols'," Journal of corporate finance, 1999, 5 (2), 169-191.

Smith, Janet Kiholm, "Trade credit and informational asymmetry," The journal of finance, 1987, 42 (4), 863-872.

Stiglitz, Joseph E and Andrew Weiss, "Credit rationing in markets with imperfect information," The American economic review, 1981, 71 (3), 393-410.

Vega-Redondo, Fernando, Complex social networks number 44, Cambridge University Press, 2007. 


\section{Appendix A. Neutrality of PU's Budget Balance}

The comparative statics results in Section 3 rest on loan distribution $P(s, \omega)$ obtained under the assumption of unconstrained budget law of motions, that is $K_{t^{\prime}}(t)$ is potentially allowed to become negative. Here I explore a possible way to reintroduce budget constraints in the analysis and show that these do not affect one of the main results of the main model. Given a type $\omega_{t^{\prime}}$, from (14) I define

$$
\ell \tilde{s}_{t^{\prime}}=\omega_{t^{\prime}}+D_{t^{\prime}}
$$

where $\tilde{s}_{t^{\prime}}$ is the upper bound to the number of loans that an agent endowed with $\omega_{t^{\prime}}$ can offer on the market. Now, I introduce the constrained distribution $\tilde{P}(s, \omega)$ as follows:

$$
\tilde{P}(s, \omega)= \begin{cases}\frac{P(s, \omega)}{P(\tilde{s}, \omega)} & \text { for } s \leq \tilde{s} \\ 0 & \text { otherwise }\end{cases}
$$

By restricting the number of loans which $t^{\prime}$ may offer on the market, the budget constraint induces a truncation on $P(s, \omega)$. I show that the properties related to FOSD depicted for example in Proposition 5 and 7 are preserved under any truncation, that is regardless to the limited liability constraint ${ }^{38}$. With no loss of generality, I prove the equivalence by assuming a loosening of the financial regulations from $\alpha^{\prime}$ to $\alpha, \alpha^{\prime}<\alpha$.

Proposition 10. Given two $C D F \tilde{P}(s, \omega ; \alpha)$ and $\tilde{P}^{\prime}\left(s, \omega ; \alpha^{\prime}\right)$ respectively obtained as the truncation of $P(s, \omega ; \alpha)$ and $P^{\prime}\left(s, \omega ; \alpha^{\prime}\right)$ as defined in (A.1), with $\alpha \geq \alpha^{\prime}$,

$$
P(s, \omega ; \alpha) \stackrel{F O}{\succ} P^{\prime}\left(s, \omega ; \alpha^{\prime}\right) \Leftrightarrow \tilde{P}(s, \omega ; \alpha) \stackrel{F O}{\succ} \tilde{P}^{\prime}\left(s, \omega ; \alpha^{\prime}\right)
$$

That is the FOSD ordering holds irrespectively of the lender's budget constraint binding.

\section{Appendix B. Proofs}

Proof of Proposition 1. (i) Given a generic endowment type $e$, from differentiation of the three components of (4) I obtain:

$$
\frac{e^{2} \chi(1+r)}{p f\left(\omega^{* *}\right)-e}+\frac{e(1+r)\left(p f\left(\omega^{* *}\right)-g e(1+r)\right)}{\left(p f\left(\omega^{* *}\right)-e\right)}-\frac{g e^{2}(1+r)^{2}}{\left(p f\left(\omega^{* *}\right)-e\right)}-(1+\tau) e=0 .
$$

The expression follows from algebraic manipulation. The second order condition de-

\footnotetext{
${ }^{38}$ Hence, I adopt a conditional FOSD, which is a stronger ordering with respect to FOSD. Indeed it is not generally the case that FOSD is preserved under truncation (see for instance Riley (2012), p.249).
} 
livers

$$
-\frac{2 e^{2}(1+r)^{2}}{\left(p f\left(\omega^{* *}\right)-e\right)}<0
$$

from which I prove the second part of the statement. From the result, it stands clear that no lending is provided for $\tau>r$. (ii) Now consider $g^{*} e$

$$
g_{e}^{*} \cdot e=\frac{p f\left(\omega^{* *}\right)(r-\tau)+e(\chi(1+r)+(1+\tau))}{2(1+r)^{2}} .
$$

The result in the statement follows directly by taking the derivative of the $\mathrm{RhS}$ with respect to $e$ and checking the condition for the sign reversal. (iii) By differentiating the lending policy at the optimum, I obtain the extremum $r^{*}$

$$
\left.\frac{\partial^{2} g e}{\partial g \partial r}\right|_{g=g^{*}}>0 \Rightarrow e<e_{p, r, \tau}^{*} \equiv \frac{(1+r)(r-\tau) p f^{\prime}\left(\omega^{* *}\right)+p f\left(\omega^{* *}\right)(1+2 \tau-r)}{\chi(1+r)+2(1+\tau)},
$$

which sets the bound as defined in the statement. Now, define

$$
\eta_{\tau}(p, r) \equiv(1+r)(r-\tau) p f^{\prime}\left(\omega^{* *}\right)+p f\left(\omega^{* *}\right)(1+2 \tau-r)
$$

and notice that $\eta_{\tau}(p, r)$ is continuous with continuous derivatives; $\lim \eta_{r \rightarrow 0}=\lim \eta_{r \rightarrow \infty}=$ $\infty$, and $\lim \eta_{p \rightarrow 0}=\infty$. Let $\theta \equiv(1+\tau) /(1+r)$. Then, $\lim \eta_{p \rightarrow \infty}=\infty$ (respectively, $\left.\lim \eta_{p \rightarrow \infty}=-\infty\right)$ for $\theta>1 / 2$ (respectively, $\theta<1 / 2$ ). Hence, there exists $p=\bar{p}_{\theta}$ such that the statement follows.

(iv) The result immediately follows from differentiating (5) relative to $\tau$. $(v)$ The result follows by noticing that $p_{\omega}$ is a standard linear transformation of the uniform distribution $p_{e}$. The result follows from application of a classical result in probability theory (see for instance Grimmett and Stirzaker, 2019).

Proof of Proposition 2. (i) Define $D^{*} \subset D$ such as the set of fully-constrained borrowers (borrowers for which given $\alpha$ and $\omega_{p, r}^{* *}$ the constraint holds tightly) and consider $\omega^{*} \in D^{*}: f\left(\omega^{*}+\alpha \omega^{*}\right)=f\left(\omega^{* *}\right)$. Because $f(\cdot)$ is a bijection, this implies that $\omega^{*}=\omega^{* *} /(1+\alpha)$. The construction of $D_{\omega}$ easily follows. (ii) The result follows from noticing that:

$$
\int_{0}^{\omega^{* *}} D_{\omega} p_{\omega} d \omega=\int_{0}^{\omega^{*}} D_{\omega} p_{\omega} d \omega+\int_{\omega^{*}}^{\omega^{* *}} D_{\omega} p_{\omega} d \omega
$$

That produces:

$$
=p_{\omega}\left(\frac{\alpha\left(\omega^{*}\right)^{2}}{2}+\frac{\left(\omega^{* *}\right)^{2}}{2}-\frac{\left(\omega^{* *}\right)^{2}}{1+\alpha}\right)
$$

Which gives as a result the area of the triangle defined on $\left[0, \omega^{* *}\right]$ with height $\alpha \omega^{*}$ from Figure 2, weighted by $p_{\omega}$. (iii) The result is straightly assessed by checking first and second derivative with respect to the arguments.

Proof of Theorem 1. The methodology of the proof follows Vega-Redondo (2007) but the resulting distribution is bivariate. I study the long-run behavior of the agents' linking dynamics by adopting a continuum approximation of the number of loans $d(t)$ issued by 
each lender at any time. Due to the continuum approximation, at most one update takes place almost surely at every instant. Hence, instead of "tracking" the stochastic evolution of lending for each specific lender $t^{\prime}$, I assume that agents that are identical in terms of endowments and issued loans on average update symmetrically, thus implying that $\xi_{t^{\prime}}$ is replaced with a deterministic rule of motion given by the following simple differential equation:

$$
\frac{d s_{t^{\prime}}(t)}{d t}=\frac{\phi_{r, \tau, \chi, \alpha, \omega^{* *}}}{t \cdot m\left(\omega_{t^{\prime}}\right) \ell \cdot s_{t^{\prime}}(t)}
$$

which is separable:

$$
\int\left(m\left(\omega_{t^{\prime}}\right) \ell \cdot s_{t^{\prime}}(t)\right) d s_{t^{\prime}}=\int \frac{\phi_{r, \tau, \chi, \alpha, \omega^{* *}}}{t} d t
$$

and has initial condition $s_{t^{\prime}}\left(t^{\prime}\right)=0$, as I assumed that every agent (including pure lenders endowed with $\left.\omega \geq \omega^{* *}\right)$ steps in the inter-firm financing market as a borrower. Integrating, I obtain

$$
s_{t^{\prime}}(t)=\sqrt{\frac{2 \phi_{r, \tau, \chi, \alpha, \omega^{* *}}}{m\left(\omega_{t^{\prime}}\right) \ell} \ln (t)+\text { constant }} .
$$

Next I obtain the constant from the initial conditions and produce the following law of motion

$$
s_{t^{\prime}}(t)=\sqrt{\frac{2 \phi_{r, \tau, \chi, \alpha, \omega^{* *}}}{m\left(\omega_{t^{\prime}}\right) \ell} \ln \left(\frac{t}{t^{\prime}}\right)},
$$

which shows that older lenders have more contracts in place, albeit at a decreasing growth rate in time. Therefore, the probability that at any given time period $t$ the node entered at $t^{\prime}$ has a certain in-degree $s_{t^{\prime}}$ is given by

$$
P\left(s_{t^{\prime}}(t)<s \mid \omega_{t^{\prime}}\right)=P\left[\sqrt{\frac{2 \phi_{r, \tau, \chi, \alpha, \omega^{* *}}}{m\left(\omega_{t^{\prime}}\right) \ell} \ln \left(\frac{t}{t^{\prime}}\right)}<d\right] .
$$

Since the only dynamical variable affecting the evolution of $s$ is the time itself (i.e. the number of borrowers entering the market), I restate the condition in terms of time interval $\left|t-t^{\prime}\right|$

$$
P\left(s_{t^{\prime}}(t)<s \mid \omega_{t^{\prime}}\right)=P\left[t \cdot e^{-\frac{m\left(\omega_{t^{\prime}}\right) \ell s^{2}}{2 \phi_{r, \tau, \chi, \alpha, \omega^{* *}}}}<t^{\prime}\right] .
$$

In order to get rid of the time-component, rewrite the above equation as the probability for a firm to enter after $t^{\prime}$. Because the probability for a firm to enter in the market after any fixed period is approximately uniform (i.e. $1 / \mathrm{t}$ ) for $t \rightarrow \infty$, such probability is given by

$$
P\left(s_{t^{\prime}}(t)<s \mid \omega_{t^{\prime}}\right)=1-\frac{1}{t} \cdot\left(t e^{-\frac{m\left(\omega_{t^{\prime}}\right) \ell s^{2}}{2 \phi_{r, \tau, \chi, \alpha, \omega^{* *}}}}\right) .
$$


Which also corresponds to the probability that at $t, t^{\prime}$ has issued $s$ loans conditional on her initial endowment $\omega_{t^{\prime}}$. The result in the main text follows by applying Bayes' rule: $P(s, \omega)=P_{\omega} \cdot P(s \mid \omega)$, from which I obtain the stationary CDF in (19). By differentiating $P(s \mid \omega)$ with respect to $s$ I derive the related density given in $(20)$.

Proof of Proposition 3. From the definition of FOSD, I need to show that

$$
P\left(s, \omega^{\prime \prime}\right) \geq P^{\prime}\left(s, \omega^{\prime}\right) \quad s \geq 0 .
$$

In order to show that the condition holds, I reformulate $P(s, \omega)$ such as $P(s, \omega)=$ $P_{\omega} P(s \mid \omega)$. From the definition of $P_{\omega}$ in Proposition 1, I know that $P_{\omega^{\prime}} \stackrel{\text { FO }}{\succ} P_{\omega^{\prime \prime}}$ to prove the statement, it it suffices to show that also $P_{\omega} P\left(s \mid \omega^{\prime}\right) \stackrel{\text { FO }}{\succ} P_{\omega} P\left(s \mid \omega^{\prime \prime}\right)$. This translates in requiring that $\frac{\partial P(s, \omega)}{\partial \omega}<0 \forall s \in \mathbb{N}$. From (19) I note that:

$$
\frac{\partial P(s \mid \omega)}{\partial \omega}=\frac{m^{\prime}(\omega) \ell \cdot s^{2}}{2 \phi_{r, \tau, \chi, \alpha, \omega^{* *}}} \cdot e^{-\frac{m(\omega) \ell \cdot s^{2}}{2 \phi_{r, \tau, \chi, \alpha, \omega^{* *}}}}<0 .
$$

In fact, due to decreasing returns to scale I know that $f^{\prime \prime}(\omega)<0$ and consequently $m^{\prime}(\omega)<0$

Proof of Proposition 4. In this proof, I assume with no loss of generality that $r=\tau$ so that $A_{p, r, \tau}=0$. (i) Notice that for $\ell \rightarrow 0$ it holds that

$$
\begin{aligned}
\bar{\iota}_{t^{\prime}}^{u}(\ell \mid x, \omega) & =\frac{p[f(\omega+x+\ell)-f(\omega+x)]}{\ell}-r \\
& =\frac{\partial f(x, \omega)}{\partial x}-r
\end{aligned}
$$

Hence, $\phi_{r, \tau, \chi, \alpha, \omega^{* *}}$ becomes

$$
\int_{0}^{\omega^{* *}} \int_{0}^{D_{\omega}}\left(p \frac{\partial f(x, \omega)}{\partial x}-r\right) \cdot p_{\omega} d x d \omega=\int_{0}^{\omega^{* *}}\left[p f\left(\omega+I_{\omega}\right)-p f(\omega)-r I_{\omega}\right] \cdot p_{\omega} d \omega .
$$

Now, I break the problem by using the endowment segmentation that splits fully constrained from non-fully constrained types

$$
\int_{0}^{\omega^{*}}[p f(\omega+\alpha \omega)] p_{\omega} d \omega+\int_{\omega^{*}}^{\omega^{* *}}\left[p f\left(\omega^{* *}\right)\right] p_{\omega} d \omega-\int_{0}^{\omega^{* *}}\left[p f(\omega) \cdot p_{\omega}\right] d \omega-\int_{0}^{\omega^{* *}}\left[r I_{\omega}\right] \cdot p_{\omega} d \omega,
$$

where $f\left(\omega^{* *}\right)$ is the optimal production target as defined in (1). I substitute $\omega^{*}=$ $\omega^{* *} /(\alpha+1)$ and exploit the result in Proposition 2. For $\omega \in \Omega$,

$$
p_{\omega}\left(\int_{0}^{\frac{\omega^{* *}}{(\alpha+1)}}[p f(\omega+\alpha \omega)] d \omega+\frac{\alpha}{1+\alpha} \omega^{* *} p f\left(\omega^{* *}\right)-\int_{0}^{\omega^{* *}} p f(\omega) d \omega-r \frac{\left(\omega^{* *}\right)^{2}}{2} \frac{\alpha}{1+\alpha}\right),
$$

which measures the average profitability of a loan for fully or partially constrained types 
of borrowers. Then. the proof is simply obtained by taking the limits over $\alpha$

$$
\begin{array}{cl}
\phi_{r, \tau, \chi, \alpha, \omega^{* *}} \rightarrow 0 & \text { for } \alpha \rightarrow 0 \\
\phi_{r, \tau, \chi, \alpha, \omega^{* *}} \rightarrow p_{\omega}\left(\left(\omega^{* *} p f\left(\omega^{* *}\right)\right)-\int_{0}^{\omega^{* *}} p f(\omega) d \omega-r \frac{\left(\omega^{* *}\right)^{2}}{2}\right) & \text { for } \alpha \rightarrow \infty .
\end{array}
$$

(ii) In order to prove the second part of the Proposition, define $K_{\omega} \equiv I_{\omega}+\omega$. Now, I recollect that $K_{\omega}=\omega(1+\alpha), \forall \omega \in\left[0, \omega^{*}\right]$ and $K_{\omega^{*}}=\omega^{* *}$. By differentiating (B.2) with respect to $\alpha$ :

$$
\begin{gathered}
\frac{d \phi_{r, \tau, \chi, \alpha, \omega^{* *}}}{d \alpha}= \\
p_{\omega}\left[\frac{1}{(1+\alpha)^{2}}\left(\omega^{* *} p f\left(\omega^{* *}\right)-r \frac{\left(\omega^{* *}\right)^{2}}{2}\right)+p f\left(\frac{\left(\omega^{* *}\right)}{(1+\alpha)}(1+\alpha)\right) \frac{-\omega^{* *}}{(1+\alpha)^{2}}+\int_{0}^{\frac{\omega^{* *}}{(\alpha+1)}} \omega p \frac{d f\left(K_{\omega}\right)}{d K} d \omega\right],
\end{gathered}
$$

which gives:

$$
\frac{d \phi_{r, \tau, \chi, \alpha, \omega^{* *}}}{d \alpha}=p_{\omega}\left[\int_{0}^{\frac{\omega^{* *}}{(\alpha+1)}} \omega p \frac{d f\left(K_{\omega}\right)}{d K_{\omega}} d \omega-r \frac{\left(\omega^{* *}\right)^{2}}{2(1+\alpha)^{2}}\right]
$$

Noticing that

$$
\frac{\left(\omega^{* *}\right)^{2}}{2(1+\alpha)^{2}}=\int_{0}^{\frac{\omega^{* *}}{(\alpha+1)}} \omega d \omega
$$

I obtain

$$
\frac{d \phi_{r, \tau, \chi, \alpha, \omega^{* *}}}{d \alpha}=p_{\omega}\left[\int_{0}^{\frac{\omega^{* *}}{(\alpha+1)}} \omega\left(p \frac{d f\left(K_{\omega}\right)}{d K_{\omega}}-r\right) d \omega\right]
$$

Now it is easy to show that (B.5) is non-negative for $\alpha \in \mathbb{R}_{+}$. From the solution of the producer's problem (1), I know that the production level for the agents whose constraint is not binding is such that $d f(K) / d K=r / p$. Hence, from (B.5), non-negativity requires that

$$
\frac{d f(K)}{d K} \geq \frac{r}{p}=\left.\frac{d f(K)}{d K}\right|_{\omega=\omega^{* *}},
$$

a condition which is always fulfilled due to DRS, for all types $\omega \in D$. Thus, given the bound in $(i), \phi_{r, \tau, \chi, \alpha, \omega^{* *}}$ is increasing in $\alpha$.

Proof of Proposition 5. In the following, as $1 / \bar{e} B_{r, \tau, \chi}$ is invariant to changes in $\alpha$, I discard it. Adapting a result from Huang, Kira and Vertinsky (Theorem 4 in Huang et al., 1978) to the current context, two conditions are required to be in place to prove the proposition: $(i) P(s, \omega ; \alpha) \underset{\succ}{\mathrm{FO}} P\left(s, \omega ; \alpha^{\prime}\right)$. (ii) $\frac{\partial P\left(s, \omega, \alpha^{\prime}\right)}{\partial \omega}<0^{39}$. In what follows, I prove that are both satisfied. (i) From the definition of FOSD:

$$
\begin{aligned}
P\left(s, \omega ; \alpha^{\prime}\right) & \geq P(s, \omega ; \alpha) \\
e^{-\frac{m(\omega ; \alpha) \ell \cdot s^{2}}{2 \phi_{r, \tau, \chi, \alpha, \omega^{* *}}}}-e^{-\frac{m\left(\omega ; \alpha^{\prime}\right) \ell \cdot s^{2}}{2 \phi_{r, \tau, \chi, \alpha^{\prime}, \omega^{* *}}}} & \geq 0, \quad \forall s>0
\end{aligned}
$$

\footnotetext{
${ }^{39}$ This implies a non-negative correlation between $\omega$ and $s$. Without such restriction, conditional dominance may not imply joint dominance (see Levy and Paroush, 1974, p.615).
} 
First, notice that $m(\omega)$ is decreasing in $\alpha$ due to DRS. Further, from Proposition 4 I know that $\phi_{r, \tau, \chi, \alpha, \omega^{* *}}$ is increasing in $\alpha$, and because $\alpha>\alpha^{\prime}$ the condition is satisfied. (ii) proved in Proposition 3.

Proof of Proposition 6. I follow the rationale of Proposition 4. First, notice from (B.2) that $\phi_{r, \tau, \chi, \alpha, \omega^{* *}} \rightarrow 0$ for $\omega^{* *} \rightarrow 0$. From differentiating (B.2) in Proposition 4 I obtain that

$$
\frac{\partial \phi_{r, \tau, \chi, \alpha, \omega^{* *}}}{\partial \omega^{* *}}=\frac{\alpha}{1+\alpha}\left(p f\left(\omega^{* *}\right)+\omega^{* *} p f^{\prime}\left(\omega^{* *}\right)-\omega^{* *} r\right),
$$

however, by recalling how I built the types' segmentation from the producer's problem, $f^{\prime}\left(\omega^{* *}\right)=r / p$. Hence:

$$
\frac{\partial \phi_{r, \tau, \chi, \alpha, \omega^{* *}}}{\partial \omega^{* *}}=\frac{\alpha}{1+\alpha}\left(p \cdot f\left(\omega^{* *}\right)\right)
$$

which is always positive.

Proof of Proposition 7. The proof is omitted as it follows as a consequence of Proposition 6 and the method used in the proof of Proposition 5

Proof of Proposition 8. Consider two ICM architectures $P\left(s, \omega ; \tau_{1}\right)$ and $P\left(s, \omega ; \tau_{2}\right)$, such that, everything else fixed, it holds that $\tau_{2} \neq \tau_{1}$. Define $\Omega$ (respectively, $\Omega^{\prime}$ ) such as the equilibrium endowment of the former (respectively, latter) ICM architecture. From Proposition 1, $\Omega \subset \Omega^{\prime}$. Fixed one type $\omega=\hat{\omega} \in \Omega$ and $s=\hat{s}>0$, a sufficient condition for FOSD to be violated in general is that the function $\psi_{r, \chi, \alpha, \omega^{* *}}\left(\tau_{1}, \tau_{2}\right)$ defined as

$$
\begin{aligned}
& \psi_{r, \chi, \alpha, \omega^{* *}}\left(\tau_{1}, \tau_{2}\right) \equiv P_{\hat{s}, \hat{\omega}}\left(\tau_{1}\right)-P_{\hat{s}, \hat{\omega}}\left(\tau_{2}\right) \\
& =\frac{\hat{\omega}-A_{p, r}\left(\tau_{1}\right)}{\bar{e} B_{r, \chi}\left(\tau_{1}\right)} \cdot\left(1-e^{-\frac{m_{\hat{\omega}} \ell \cdot \hat{s}^{2}}{2 \phi_{r, \chi, \alpha, \omega * *}\left(\tau_{1}\right)}}\right)-\frac{\hat{\omega}-A_{p, r}\left(\tau_{2}\right)}{\bar{e} B_{r, \chi}\left(\tau_{2}\right)} \cdot\left(1-e^{-\frac{m_{\hat{\omega}} \ell \cdot \hat{s}^{2}}{2 \phi_{r, \chi, \alpha, \omega^{* *}}\left(\tau_{2}\right)}}\right),
\end{aligned}
$$

changes sign at least once for $\tau_{2}>\tau_{1}>0$. This is achieved by showing that $\psi_{r, \chi, \alpha, \omega^{* *}}$ is not monotonic in $\left(\tau_{1}-\tau_{2}\right)$. Rewrite the elements of (B.2) changing in $\tau_{1}$

$$
\int_{A_{p, r}\left(\tau_{1}\right)}^{\frac{\omega^{* *}}{(1+\alpha)}} p f(\omega(1+\alpha)) d \omega-\int_{A_{p, r}\left(\tau_{1}\right)}^{\omega^{* *}} p f(\omega) d \omega,
$$

where I used the fact that $\inf \Omega=A_{p, r, \tau}$ to decompose $p_{\omega}$ and discard $1 / \bar{e} B_{r, \chi}(\tau)$. This is possible ${ }^{40}$ as $1 / \bar{e} B_{r, \chi}(\tau)$ is always positive and monotonic in $\tau$ for $\omega \in \Omega$, with a multiplicative effect on terms within parentheses of (B.2). Now, call $e_{1}(\tau)$ (respectively, $\left.e_{2}(\tau)\right)$ such as the type achieving $\omega_{e_{1}(\tau)}=\omega^{* *} /(1+\alpha)$ (respectively, $\left.\omega_{e_{2}(\tau)}=\omega^{* *}\right)$ from the

\footnotetext{
${ }^{40}$ In untabled results, I show that the introduction of $1 / \bar{e} B_{r, \chi}(\tau)$ makes the computation of (B.7) more cumbersome without affecting the qualitative result of the proof.
} 
bank's problem in (5). For convenience ${ }^{41}$ in the following I use the sum approximation

$$
\begin{gathered}
\sum_{e=0}^{e_{1}(\tau)} p f\left(\left(A_{p, r}(\tau)+e B_{r, \chi}(\tau)\right)(1+\alpha)\right)-\sum_{e=0}^{e_{2}(\tau)} p f\left(A_{p, r}(\tau)+e B_{r, \chi}(\tau)\right) \\
\sum_{e=0}^{e_{1}(\tau)}\left(p f\left(\left(A_{p, r}(\tau)+e B_{r, \chi}(\tau)\right)(1+\alpha)\right)-p f\left(A_{p, r}(\tau)+e B_{r, \chi}(\tau)\right)\right)-\sum_{e=e_{1}(\tau)+1}^{e_{2}(\tau)} p f\left(A_{p, r}(\tau)+e B_{r, \chi}(\tau)\right) .
\end{gathered}
$$

I specify as ad-hoc production function $f(\cdot)=\log (\cdot)$ and rewrite

$$
\begin{aligned}
& \sum_{e=0}^{e_{1}(\tau)}\left(p \log \left(A_{p, r}(\tau)+e B_{r, \chi}(\tau)\right)-p \log \left(A_{p, r}(\tau)+e B_{r, \chi}(\tau)\right)\right)+\sum_{e=0}^{e_{1}(\tau)} p \log (1+\alpha) \\
& \quad-\sum_{e=e_{1}(\tau)+1}^{e_{2}(\tau)} p \log \left(A_{p, r}(\tau)+e B_{r, \chi}(\tau)\right),
\end{aligned}
$$

from which I get

$$
\bar{\psi}_{r, \chi, \alpha, \omega^{* *}}(\tau) \equiv \sum_{e=0}^{e_{1}(\tau)} p \log (1+\alpha)-\sum_{e=e_{1}(\tau)+1}^{e_{2}(\tau)} p \log \left(A_{p, r}(\tau)+e B_{r, \chi}(\tau)\right) .
$$

Holding $e_{1}$ and $e_{2}$ fixed, the first sum in (B.7) grows linearly in $\tau$. Relative to the second sum, by differentiating both terms within $\log (\cdot)$ it is immediate to see that the sum grows (respectively, shrinks) in $\tau$ for $e>\hat{e}_{p, r}$ (respectively, $e \leq \hat{e}_{p, r}$ ), where $\hat{e}_{p, r} \equiv p \log \left(\omega^{* *}\right)$. Hence, the net effect of a shock $\tau_{2}>\tau_{1}$ is an equilibrium credit expansion (respectively, restriction) for any $\mathrm{PU} i \in N$ such that $e_{i} \geq \hat{e}_{p, r}$ (respectively, $e_{i}<\hat{e}_{p, r}$ ). Overall, the behavior of (B.7) (and, more in general of $\phi_{r, \chi, \alpha, \omega^{* *}}(\tau)$ ) falls within three cases. Consider sets $E_{1}, E_{2}$ and $E_{S}$ as defined in the main text. (i) $\hat{e}_{p, r} \leq e_{1}\left(\tau_{1}\right)<e_{2}\left(\tau_{1}\right)$. In this case, $e_{1}\left(\tau_{2}\right) \leq e_{1}\left(\tau_{1}\right)$ and $e_{2}\left(\tau_{2}\right) \leq e_{2}\left(\tau_{1}\right)$. Hence,

$$
\bar{\psi}\left(\tau_{2}\right)-\bar{\psi}\left(\tau_{1}\right)<-\sum_{e=e_{1}\left(\tau_{2}\right)+1}^{e_{2}\left(\tau_{2}\right)} p\left(\log \left(A_{p, r}\left(\tau_{2}\right)+e B_{r, \chi}\left(\tau_{2}\right)\right)-\log \left(A_{p, r}\left(\tau_{1}\right)+e B_{r, \chi}\left(\tau_{1}\right)\right)\right)<0 .
$$

whereas all types $e<e_{1}$ are invariant to stricter bank rationing, hence total demand for ICM credit shrinks as a result of at least one type $e \in E_{1}$ switching to $E_{2}$. (ii) $e_{1}\left(\tau_{1}\right)<e_{2}\left(\tau_{1}\right)<\hat{e}_{p, r}$. In this case, $e_{1}\left(\tau_{2}\right)>e_{1}\left(\tau_{1}\right)$ and $e_{2}\left(\tau_{2}\right)>e_{2}\left(\tau_{1}\right)$, and

$$
\begin{aligned}
\bar{\psi}\left(\tau_{2}\right) & -\bar{\psi}\left(\tau_{1}\right)=\left(e_{1}\left(\tau_{2}\right)-e_{1}\left(\tau_{1}\right) \cdot p \log (1+\alpha)+\sum_{e=e_{1}\left(\tau_{1}\right)+1}^{e_{1}\left(\tau_{2}\right)} p \log \left(A_{p, r}\left(\tau_{1}\right)+e B_{r, \chi}\left(\tau_{1}\right)\right)\right. \\
& -\left(\sum_{e=e_{1}\left(\tau_{2}\right)+1}^{e_{2}\left(\tau_{2}\right)} p \log \left(A_{p, r}\left(\tau_{2}\right)+e B_{r, \chi}\left(\tau_{2}\right)\right)-\sum_{e=e_{1}\left(\tau_{1}\right)+1}^{e_{2}\left(\tau_{1}\right)} p \log \left(A_{p, r}\left(\tau_{1}\right)+e B_{r, \chi}\left(\tau_{1}\right)\right)\right),
\end{aligned}
$$

where the first (respectively, the second) line accounts for all types switching from $E_{2}$ to $E_{1}$ (respectively, from $E_{S}$ to $E_{2}$ ). Notice that for each type $e^{\prime}$ switching from $E_{2}$ to $E_{1}$

\footnotetext{
${ }^{41}$ The sum notation is simply used to emphasize the effect of changes to the types' structure as induced by changes to $e_{1}(\tau)$ and $e_{2}(\tau)$ but it does not alter the qualitative structure and result of the proof.
} 
following $\tau_{2}>\tau_{1}$ the first line positively compounds a linear and a log increment as the support of the first sum expands. In the second line, for each shock $\tau_{2}>\tau_{1}$, the support of the first sum slides toward higher types, whereas the second sum is fixed. Therefore, for $\alpha$ small enough, it is possible to find $\tau_{2}>\bar{\tau}$ (respectively, $\tau_{2}<\bar{\tau}$ ) such that the second sum dominates (respectively, is dominated by) all other terms in the expression. (iii) $e_{1}\left(\tau_{1}\right)<\hat{e}_{p, r} \leq e_{2}\left(\tau_{1}\right)$. Here, $e_{1}\left(\tau_{2}\right) \geq e_{1}\left(\tau_{1}\right)$ and $e_{2}\left(\tau_{2}\right) \leq e_{2}\left(\tau_{1}\right)$, and

$$
\begin{aligned}
\bar{\psi}\left(\tau_{2}\right) & -\bar{\psi}\left(\tau_{1}\right)=\left(e_{1}\left(\tau_{2}\right)-e_{1}\left(\tau_{1}\right) \cdot p \log (1+\alpha)+\sum_{e=e_{1}\left(\tau_{1}\right)+1}^{e_{1}\left(\tau_{2}\right)} p \log \left(A_{p, r}\left(\tau_{1}\right)+e B_{r, \chi}\left(\tau_{1}\right)\right)\right. \\
& -\left(\sum_{e=e_{1}\left(\tau_{2}\right)+1}^{\hat{e}_{p, r}} p \log \left(A_{p, r}\left(\tau_{2}\right)+e B_{r, \chi}\left(\tau_{2}\right)\right)-\sum_{e=e_{1}\left(\tau_{1}\right)+1}^{\hat{e}_{p, r}} p \log \left(A_{p, r}\left(\tau_{1}\right)+e B_{r, \chi}\left(\tau_{1}\right)\right)\right) \\
& -\left(\sum_{e=\hat{e}_{p, r}+1}^{e_{2}\left(\tau_{2}\right)} p \log \left(A_{p, r}\left(\tau_{2}\right)+e B_{r, \chi}\left(\tau_{2}\right)\right)-\sum_{e=\hat{e}_{p, r}+1}^{e_{2}\left(\tau_{1}\right)} p \log \left(A_{p, r}\left(\tau_{1}\right)+e B_{r, \chi}\left(\tau_{1}\right)\right)\right)
\end{aligned}
$$

where again the first line is as in case $(i i)$, the second (respectively, third) line accounts for types in $E_{2}$ experiencing a credit cut (respectively, expansion) following the hike. Depending on the specific bank policy and the position of $\hat{e}_{p, r}$, the forth sum may dominate (respectively, be dominated by) all other terms in the expression. Hence, the sign of $\psi_{r, \chi, \alpha, \omega^{* *}}\left(\tau_{2}\right)-\psi_{r, \chi, \alpha, \omega^{* *}}\left(\tau_{1}\right)$ depends on the granular values of $\tau_{1}$ and $\tau_{2}$ given $\alpha$. The coexistence of cases $(i)-(i i i)$ guarantees that $\bar{\psi}_{r, \chi, \alpha, \omega^{* *}}(\tau)$ and $\phi_{r, \chi, \alpha, \omega^{* *}}(\tau)$ are not monotonic in general for $\tau_{1}, \tau_{2}>0$. Now, to show that $\psi_{r, \chi, \alpha, \omega^{* *}}\left(\tau_{1}, \tau_{2}\right)$ is not monotonic in $\left(\tau_{1}-\tau_{2}\right)$, notice that

$$
\frac{d}{d \tau}\left[\frac{\hat{\omega}-A_{p, r}(\tau)}{\bar{e} B_{r, \chi}(\tau)}\right]=\frac{(1+r)(p(1+\chi) \log (p / r)--2 \hat{\omega}(1+r))}{\bar{e}(1+\chi(1+r)+\tau)^{2}},
$$

so that the above is sign-invariant in $\tau$. To show that $\psi_{r, \chi, \alpha, \omega^{* *}}\left(\tau_{1}, \tau_{2}\right)$ is generally nonmonotonic in $\left(\tau_{1}-\tau_{2}\right)$, it then suffices to select $\hat{\omega}=p(1+\chi) \log (p / r) / 2(1+r)$ to annihilate the effect of $(\hat{\omega}-A) / \bar{e} B$ and the result of the Proposition follows immediately from the fact that $\bar{\psi}_{r, \chi, \alpha, \omega^{* *}}(\tau)$ is non-monotonic.

Proof of Proposition 9. Let two ICM architectures $P\left(s, \omega ; r_{1}\right)$ and $P\left(s, \omega ; r_{2}\right)$ such that, everything else fixed, $r_{2}>r_{1}$. Set $\omega=\hat{\omega}$ and define the function $\psi_{\tau, \chi, \alpha}\left(r_{1}, r_{2}\right)$ such as

$$
\begin{aligned}
\psi_{\tau, \chi, \alpha}\left(r_{1}, r_{2}\right) & \equiv P_{\hat{s}, \hat{\omega}}\left(r_{1}\right)-P_{\hat{s}, \hat{\omega}}\left(r_{2}\right) \\
& =\frac{\hat{\omega}-A_{p, \tau}\left(r_{1}\right)}{\bar{e} B_{\tau, \chi}\left(r_{1}\right)} \cdot\left(1-e^{-\frac{m_{\hat{\omega}} \ell \cdot \hat{s}^{2}}{2 \phi_{\tau, \chi, \alpha}\left(r_{1}\right)}}\right)-\frac{\hat{\omega}-A_{p, \tau}\left(r_{2}\right)}{\bar{e} B_{\tau, \chi}\left(r_{2}\right)} \cdot\left(1-e^{-\frac{m_{\hat{\omega}} \ell \cdot \hat{s}^{2}}{2 \phi_{\tau, \chi, \alpha}\left(r_{2}\right)}}\right) .
\end{aligned}
$$

(1) Let $r_{2}$ and $r_{1}, r_{2}>r_{1}$ such that $\theta<1 / 2$ and let $p>\bar{p}_{\theta}$ so that $e_{p, r, \tau}^{*}<0$. From Proposition 1.3 and (B.1), $\omega_{e}(r)$ is decreasing in $r$. Indeed, $r_{2}>r_{1}$ implies that lending shrinks, $\omega_{e}\left(r_{1}\right)>\omega_{e}\left(r_{2}\right) \forall e>0$. Furthermore, fixed a bank lending policy $\omega_{e}$, from (B.6) $\phi_{r, \tau, \chi, \alpha}\left(\omega^{* *}\right)$ is monotonic and growing in $p / r$, hence $\phi_{\tau, \chi, \alpha, \omega^{* *}}(r)$ is monotonic and decreasing in $r$ for a fixed lending policy $\omega_{e}$. Therefore, when the banking policy varies 
as a result of the shock, the two effects compound and this guarantees that $\phi_{\tau, \chi, \alpha, \omega^{* *}}(r)$ is monotonic and decreasing as well. Now, define

$$
\hat{\psi}_{\tau, \chi, \alpha} \equiv \frac{d}{d r}\left[\frac{A_{p, \tau}(r)}{\bar{e} B_{\tau, \chi}(r)}\right]=\frac{p\left(f\left(\omega^{* *}(r)\right)+(r-\tau) f^{\prime}\left(\omega^{* *}(r)\right)\right)}{2 \bar{e} \chi(1+\tau)}>0 .
$$

Hence, it holds that $\psi_{\tau, \chi, \alpha}\left(r_{1}, r_{2}\right)>0$. (2) Consider the cases where conditions in (1) do not hold. From Proposition 1.3 and (B.1), $e_{p, r, \tau}^{*}>0$. Hence, one can easily show that $\psi_{\tau, \chi, \alpha}\left(r_{1}, r_{2}\right)$ is non-monotonic in general by following the same procedure used in the proof of Proposition 9.

Proof of Proposition 10. The structure of the proof follows the one of Proposition 5. However, while condition ( $i i)$ is straightforwardly assessed, condition $(i)$ deserves some care. Given $\omega_{t^{\prime}}=\omega$, I prove that

$$
\tilde{P}(s, \omega ; \alpha) \stackrel{\text { FO }}{\succ} \tilde{P}^{\prime}\left(s, \omega ; \alpha^{\prime}\right) \quad \forall s \leq \tilde{s}(\omega) .
$$

With a small abuse of notation, let $A \equiv \frac{m(\omega, \alpha) \ell}{2 \phi_{r, \tau, \chi, \alpha, \omega * *}}$ and $A^{\prime} \equiv \frac{m\left(\omega, \alpha^{\prime}\right) \ell}{2 \phi_{\alpha^{\prime}, \omega^{* *}}}$, where $m^{\prime}(\cdot) \geq m(\cdot)$ with strict inequality if $\omega \in\left\{0, \omega^{*}\right\}$ and $A^{\prime} \geq A$. Hence, I rephrase the conditional FOSD above in the following

$$
\frac{1-e^{-A s^{2}}}{1-e^{-A \tilde{s}^{2}}} \leq \frac{1-e^{-A^{\prime} s^{2}}}{1-e^{-A^{\prime} \tilde{s}^{2}}} \quad \forall s \in[0, \tilde{s}(\omega)]
$$

or,

$$
\frac{1-e^{-A s^{2}}}{1-e^{-A^{\prime} \tilde{s}^{2}}} \leq \frac{1-e^{-A \tilde{s}^{2}}}{1-e^{-A^{\prime} \tilde{s}^{2}}} \quad \forall s \in[0, \tilde{s}(\omega)]
$$

where it is clear that both the ratios are positive and greater than unity. Hence, it suffices to show that

$$
\begin{gathered}
1-e^{-A s^{2}}-\left(1-e^{-A^{\prime} \tilde{s}^{2}}\right) \leq 1-e^{-A \tilde{s}^{2}}-\left(1-e^{-A^{\prime} \tilde{s}^{2}}\right) \\
e^{-A s^{2}}-e^{-A^{\prime} s^{2}} \geq e^{-A \tilde{s}^{2}}-e^{-A^{\prime} \tilde{s}^{2}},
\end{gathered}
$$

which can be stated as

$$
g(s) \geq \tilde{B},
$$

where $\tilde{B}$ is a positive constant. Now, notice that $g(s)$ is monotonic and $g(\tilde{s})=\tilde{B}$. In order to prove the proposition, it suffices to show that $g(s)$ is decreasing over the support. By differentiating the left side of the equation above, it is immediate to show that

$$
2 s\left(A^{\prime} e^{-A^{\prime} s^{2}}-A e^{-A s^{2}}\right) \leq 0 .
$$

In fact, from the component in brackets I obtain that

$$
\log \left(A^{\prime}\right)-\log (A) \leq s^{2}\left(A^{\prime}-A^{\prime}\right),
$$

which is always the case for all the $s$ in the support. 